\title{
Olanzapine in Chinese patients with schizophrenia or bipolar disorder: a systematic literature review
}

\author{
This article was published in the following Dove Press journal: \\ Neuropsychiatric Disease and Treatment \\ 16 May 2014 \\ Number of times this article has been viewed
}

\author{
Hai Bo Haber Xue' \\ Li Liu' \\ Hena Zhang ${ }^{2}$ \\ William Montgomery ${ }^{3}$ \\ Tamás Treuer ${ }^{4}$ \\ 'Lilly Suzhou Pharmaceutical Co, \\ Ltd, Shanghai Branch, Shanghai, \\ ${ }^{2}$ China Pharmaceutical University, \\ Nanjing, People's Republic of China; \\ ${ }^{3}$ Eli Lilly Australia Pty Ltd, West Ryde, \\ Australia; ${ }^{4}$ Eli Lilly \& Co, Budapest, \\ Hungary
}

Background: Despite the burden of schizophrenia and bipolar disorder in the Chinese population, country-specific data to guide practitioners regarding antipsychotic therapy are lacking. The primary aim of this systematic review was to examine evidence of the efficacy, effectiveness, and safety of olanzapine in Chinese populations.

Methods: A systematic literature search was conducted using databases covering international and Chinese core journals using search terms related to schizophrenia and bipolar disorder, specified countries (People's Republic of China, Hong Kong, Taiwan), and olanzapine treatment. Following initial screening, inclusion and exclusion criteria were applied to the search results to identify relevant studies from which data were extracted.

Results: A total of 489 publications were retrieved and 61 studies were identified for inclusion. Most studies were related to schizophrenia $(n=54)$, with six studies related to bipolar disorder and one study related to both conditions. The quality of study methods and reporting in international journals was noticeably better than in Chinese language journals. Most studies included relatively small patient populations and were of short duration. The efficacy of olanzapine in Chinese populations was confirmed by multiple comparative and noncomparative studies that found statistically significant reductions in symptom measures in studies conducted for $\geq 6$ weeks (schizophrenia) or $\geq 3$ weeks (bipolar disorder). Findings related to effectiveness (treatment discontinuation, quality of life, and neurocognitive improvements) were generally consistent with those observed in non-Chinese populations. No new safety signals specific for Chinese populations were raised for olanzapine.

Conclusion: Chinese and non-Chinese populations with schizophrenia or bipolar disorder treated with olanzapine display broadly similar responses. Differences between these populations, especially in relation to the relative efficacy of olanzapine versus other antipsychotics, may warrant further investigation via studies incorporating both populations. Use of local data to provide evidence for practice guidelines should be encouraged, and may promote ongoing improvements in the quality of research and study reporting.

Keywords: bipolar disorder, schizophrenia, Chinese, olanzapine, outcomes

\section{Introduction}

Neuropsychiatric conditions are the most common form of chronic disease in the People's Republic of China and represent an enormous unmet health care need., ${ }^{1,2}$ A large-scale review estimated that the 1-month prevalence of any mental disorder among mainland Chinese is $17.5 \%$, including a prevalence of mood disorders of $6.1 \%$ and a prevalence of psychotic disorders of $1.0 \%{ }^{2}$ In terms of addressing the challenge of chronic psychotic disorders, evidence from Chinese and non-Chinese populations suggests that effective treatment of psychotic disorders improves patient outcomes. ${ }^{3,4}$
Correspondence: Hai Bo Haber Xue Medical Affairs, Lilly Suzhou Pharmaceutical Co, Ltd, Shanghai Branch, 2IF, I Corporate Avenue, 222 Hu Bin Road 20002I, Shanghai, People's Republic of China Tel +862 2I 2302 I333 Fax $+8621 \quad 2302 \quad 1487$ Email xue_hai_bo_haber@lilly.com 
However, synthesis of data from individual trials of antipsychotic agents to provide clinically useful recommendations for clinicians has mainly focused on non-Chinese populations. $^{5}$

Among Chinese populations, chronic psychotic disorders and their treatment have distinct characteristics, many of which may reflect social and cultural norms. Most Chinese people with chronic mental disorders live with their families, who carry a heavy burden of care, often with limited respite. ${ }^{6}$ Antipsychotic polypharmacy, defined as the concurrent use of more than one antipsychotic drug, is also common in Chinese populations. A polypharmacy rate of $36.8 \%$ on the Chinese mainland has been reported using data from $2008 .^{7}$ There is some evidence that sociocultural factors in the People's Republic of China, such as the general tendency of Chinese traditional medicine to employ multiple ingredients in single preparations, may underlie these high polypharmacy rates. ${ }^{8}$ Sociocultural factors related to norms for social conduct and particularly the need for social harmony may also cause treating physicians and people in the community to be sensitive to the expression of behavioral symptoms, such as poor impulse control and hostility by people with psychotic disorders. ${ }^{9}$ Disruption of social order and harmony is considered a serious transgression of social norms according to the Chinese world view. These characteristics provide a strong rationale to review antipsychotic treatment studies in Chinese populations to understand the similarities and differences in patient outcomes compared with those of non-Chinese populations.

In the People's Republic of China, olanzapine (Zyprexa ${ }^{\circledR}$; Eli Lilly and Company, Indianapolis, IN, USA) is approved for the acute treatment of schizophrenia, maintenance of clinical improvement in patients who respond to initial treatment, short-term treatment of moderate to severe mania, and the prevention of recurrence of bipolar disorder in patients who have responded to olanzapine. ${ }^{10}$ In the People's Republic of China olanzapine was approved for use in schizophrenia in 1998 and for bipolar disorder in 2006. Prescribing patterns of antipsychotics in the People's Republic of China have changed substantially in recent years. ${ }^{11,12}$ Data from various sources, including sales figures and hospital medication usage records, show that use of older typical antipsychotics such as chlorpromazine decreased between 2008 and 2011, while there has been a corresponding increase in the use of atypical antipsychotics. ${ }^{11,12}$ Further, clozapine, which was a popular antipsychotic choice in the People's Republic of China, has also fallen in usage. ${ }^{11,12}$ One study of prescribing patterns in Asia, including Chinese patients, found that risperidone was the most commonly used second-generation atypical antipsychotic (31.5\%), followed by olanzapine (13.1\%), quetiapine (7.3\%), and aripiprazole (1.9\%). ${ }^{13}$ Studies from the People's Republic of China also reveal that risperidone is used to a greater extent than olanzapine, although the recent rate of increase in olanzapine use has been greater. ${ }^{11}$ Since approval, information on olanzapine for the treatment of schizophrenia and bipolar disorder in the People's Republic of China has been mainly derived from pivotal registration trials, numerous active comparator studies, and long-term observational studies, which have been extensively reviewed. ${ }^{14-16}$ However, these studies, published in international journals, were conducted largely in the USA, Europe, and, to a lesser degree, Asia. Thus, the applicability of these studies to Chinese populations is not known. This lack of specific information on olanzapine in Chinese populations, combined with the increasing use of olanzapine in the People's Republic of China, form the key rationale for focusing on olanzapine in this review. The major hypothesis of this review is that, despite cultural and other differences, Chinese populations with psychotic disorders are not substantially different from other populations in terms of response to effective interventions.

The primary objective of this systematic literature review is to examine the clinical evidence for the efficacy, effectiveness, and safety of olanzapine in Chinese populations with schizophrenia or bipolar disorder. It also identifies opportunities for further research in the People's Republic of China to improve the care of patients with schizophrenia or bipolar disorder.

\section{Methods}

\section{Search strategy and terms}

A prospective systematic literature search strategy to retrieve publications was developed. For the international literature, the electronic databases MEDLINE via PubMed, EMBASE, Cochrane Library, ClinicalTrials.gov, and Eli Lilly internal and external trial registries were used. For Chinese language publications, databases of the People's Republic of China National Knowledge Infrastructure (http://www.cnki.net), Wan Fang database (http://www. wanfangdata.com.cn), and the VIP Information/Chinese Scientific Journals Database (http://www.cqvip.com) were used. For the international databases, the search period was from January 1, 1996 to May 22, 2013 (search date) except for ClinicalTrials.gov, which was searched from January 1, 2000 to May 22, 2013. For the Chinese language databases, the search period was from January 1, 1996 to May 29, 2013 (search date). 
Search terms were chosen relevant to the categories of country, disease state, and treatment using standardized terms where applicable. For the category of country, the search terms were "China", "Chinese", "Taiwan", "Taiwanese", and "Hong Kong". For the category of disease state, the search terms were "schizophrenia", "bipolar disorder", "mania", "mixed episodes", "manic episodes", and "agitation". For the category of treatment, the search terms were "olanzapine”, “Zyprexa”, and "LY170053”. For all databases, search terms within each category were combined using the Boolean operator OR. Categories were then combined using the Boolean operator AND.

Database-specific limits were used to exclude abstracts and publications that did not include original, reportable data on multiple patients (including letters to the editor, case reports, editorials, and narrative reviews). Importantly, search of Chinese language publications was restricted to core medical journals, which met certain bibliometric quality standards including qualitative peer review. ${ }^{17,18}$ The core journal categories of General Health and Medical (37 journals), Neurology and Psychiatry (nine journals), and Pharmacy (16 journals) were used.

\section{Inclusion and exclusion criteria}

Studies were included if they met the following criteria: Chinese patients with schizophrenia or bipolar disorder wholly residing in mainland China, Taiwan, or Hong Kong; study duration $\geq 3$ weeks (for bipolar disorder) or $\geq 6$ weeks (for schizophrenia); on-label use of olanzapine in terms of dose and indication; published evidence from randomized controlled trials (RCTs), systematic reviews, or observational studies (prospective and retrospective; crossover and noncrossover) including cross-sectional studies and longitudinal (eg, cohort) studies. Study durations were selected based on the typical time required for treatment response and commonly used in clinical studies of these conditions. Included studies also had to report numerical data on at least one recognized outcome measure related to efficacy, effectiveness, or safety/tolerability. Studies were specifically excluded if they were duplicate publications or contained previously reported data, had no numerically reportable data on at least one relevant outcome measure, did not include olanzapine treatment, or were published evidence from case studies, case series, narrative reviews, editorials, or letters to the editor.

\section{Data extraction}

All authors contributed to the literature search strategy, inclusion/exclusion criteria, and reporting of outcomes.
For non-Chinese language publications, one person (not an author) conducted the literature search and screened the title and abstract of publications identified by the search criteria. For Chinese language publications, two Chinese speaking authors conducted the literature search, and screened the title and abstract of publications identified by the search against the inclusion/exclusion criteria.

Full publications considered for possible inclusion were retrieved and rescreened using the inclusion/exclusion criteria. The reference lists of systematic and narrative reviews were also screened to identify additional publications for inclusion. Chinese language publications were translated into English by one of the Chinese authors and each translation was verified by another author.

One person (not an author) extracted data into an Excel $^{\mathbb{B}}$ (Microsoft Corporation, Redmond, WA, USA) spreadsheet using the following fields: study design and location; study duration; number of participants; mean age; sex; diagnosis; disease characteristics (eg, severity); comorbid conditions; treatment characteristics; efficacy (symptom control) measures; effectiveness measures; and safety and tolerability information, including adverse events, vital signs, laboratory investigations, and adverse event-related study discontinuations.

\section{Results}

\section{Literature search results}

A total of 489 publications were retrieved from the literature databases (Figure 1). In total, 431 publications were excluded because they did not meet the eligibility criteria (Figure 1). The most common reasons for exclusion were the lack of an olanzapine treatment arm and the study not being conducted in a specified country. Incorporating three additional eligible publications obtained from hand searching, a total of 61 publications were included in the review.

\section{Publication characteristics}

Most publications were related exclusively to schizophrenia $(n=54)$, whereas six publications related exclusively to bipolar disorder and one study related to both conditions (Figure 1 and Table 1). The 61 publications comprised both interventional $(n=43)$ and noninterventional studies $(n=18)$. Interventional studies consisted of RCTs ( $\mathrm{n}=33$ ), including blinded and open-label trials, and nonrandomized, openlabel studies $(\mathrm{n}=10)$. Noninterventional studies consisted of cohort studies ( $n=3)$, cross-sectional studies $(n=3)$, case-control studies $(n=3)$, a retrospective review $(n=1)$, a distributed network model $(n=1)$, a crossover observational 


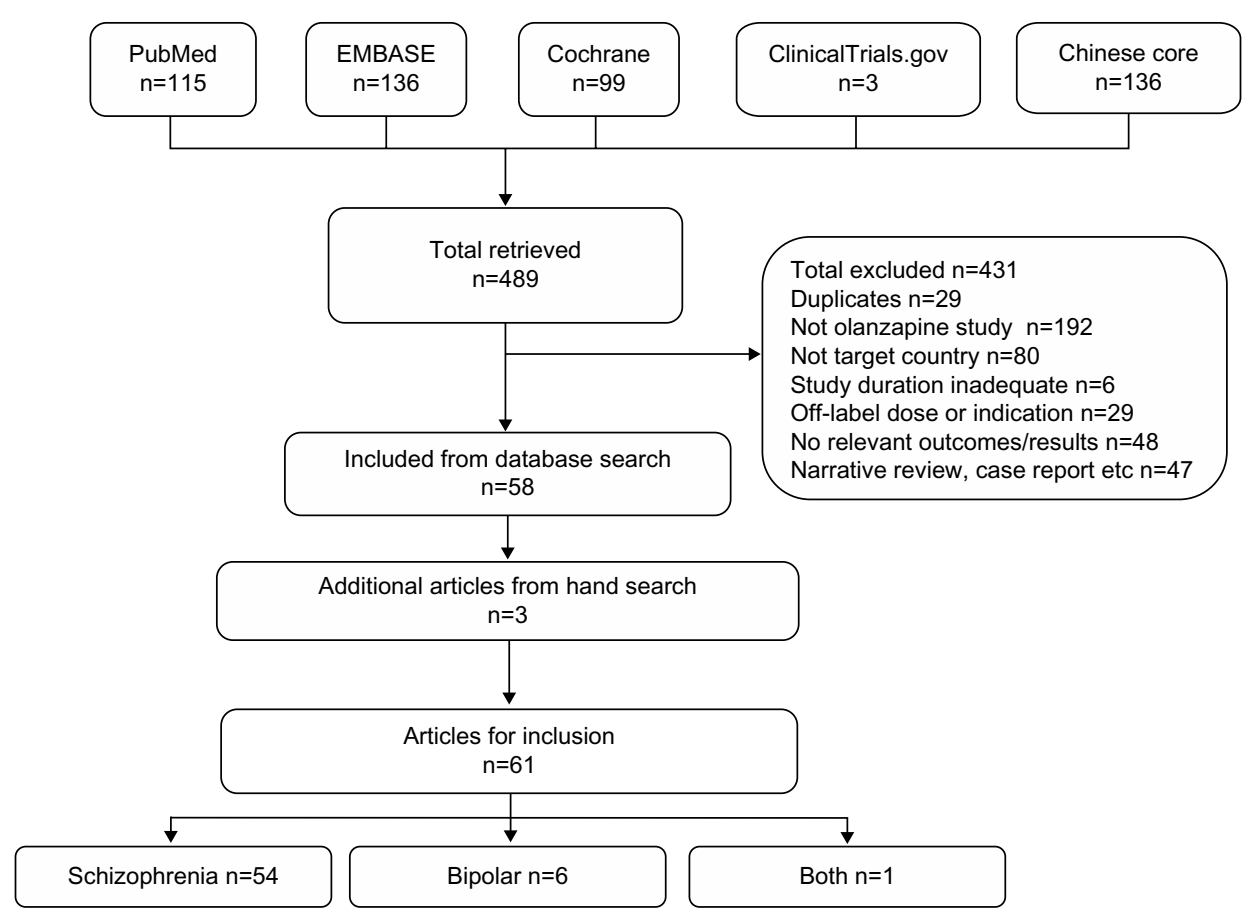

Figure I Publication flow diagram.

study ( $\mathrm{n}=1)$, and other observational studies with one or more treatment arms $(n=6)$. Importantly, no specific systematic review of Chinese studies of olanzapine was uncovered by the literature search.

Publications were either published in international peerreviewed journals $(n=29)$ or Chinese core journals $(n=32)$. Although studies published in international and Chinese journals were both peer-reviewed, they differed considerably in terms of methodological rigor and reporting. Potential sources of bias were more apparent in studies from Chinese core journals. Specifically, in most comparative studies from Chinese core journals, allocation procedures for randomization, presence or absence of blinding, baseline demographic data, or the number of patients who completed the study (associated with potential attrition bias) were poorly reported or not reported (Table 1). Further, methods for minimizing the effect of confounding variables through stratification, multivariable analysis, or other statistical methods were not evident in studies published in Chinese core journals. In contrast, key details were described in most comparative trials published in international journals, which also outlined potential sources of bias within the limitations of the study report.

A variety of efficacy, effectiveness, and safety/tolerability outcomes were used throughout the included studies (Table 1). Quantitative synthesis of the response data was not possible because of the differences in methods, outcome measures, and definitions of response reported across the studies.

\section{Study characteristics}

The included studies assessed efficacy, effectiveness, safety, or various combinations of these outcomes. In terms of efficacy assessment, all comparative studies in schizophrenia were RCTs, which were typically short and enrolled less than 50 patients per group (Table 2). The mean duration of these RCTs was 9.5 weeks (median 8 weeks, range 6-24 weeks) and the mean number of enrolled patients was 99.4 patients (median 72.5, range 30-372). Noncomparative efficacy studies in schizophrenia were open-label $(n=8)$ or observational $(n=3)$ studies, with a mean duration of 25.8 weeks (median 8 weeks, range 6-78 weeks) and a mean number of enrolled patients of 351.2 (median 48, range 12-1,267; Table 3). Regarding bipolar disorder efficacy, comparative studies were mostly RCTs and had a mean duration of 6 weeks and mean population size of 176.6 patients (median 120, range 49-514; Table 4).

Studies assessing effectiveness were made up of RCTs $(n=3),{ }^{19-21}$ nonrandomized open-label studies $(n=2),{ }^{22,23}$ observational studies $(\mathrm{n}=2),{ }^{24,25}$ a cross-sectional comparative study, ${ }^{26}$ and a cohort study. ${ }^{27}$ The mean duration of these studies was 37 weeks (median 52, range 12-52) and the mean number of enrolled patients was 690.3 (median 698, range 60-1,227). 


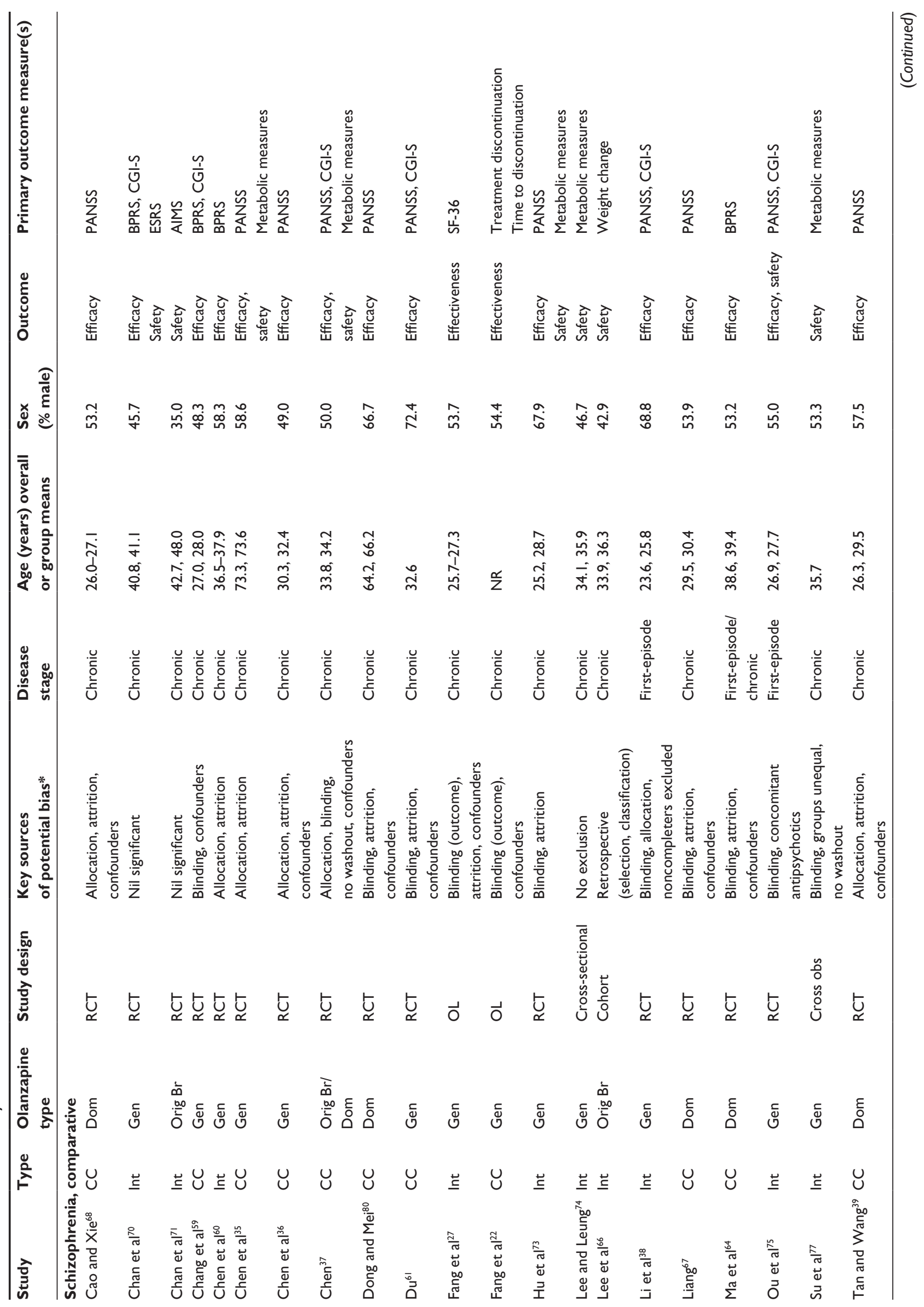




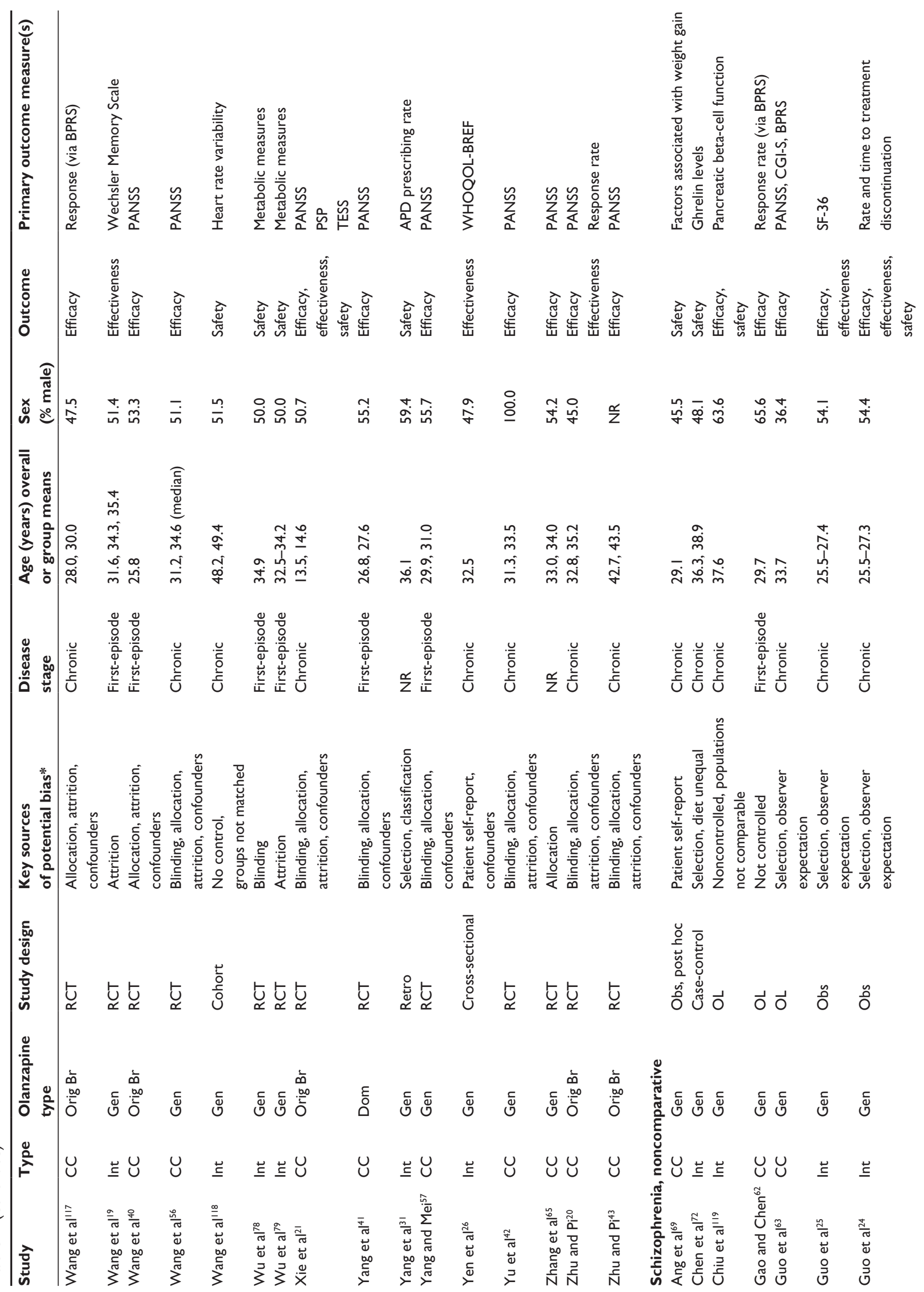




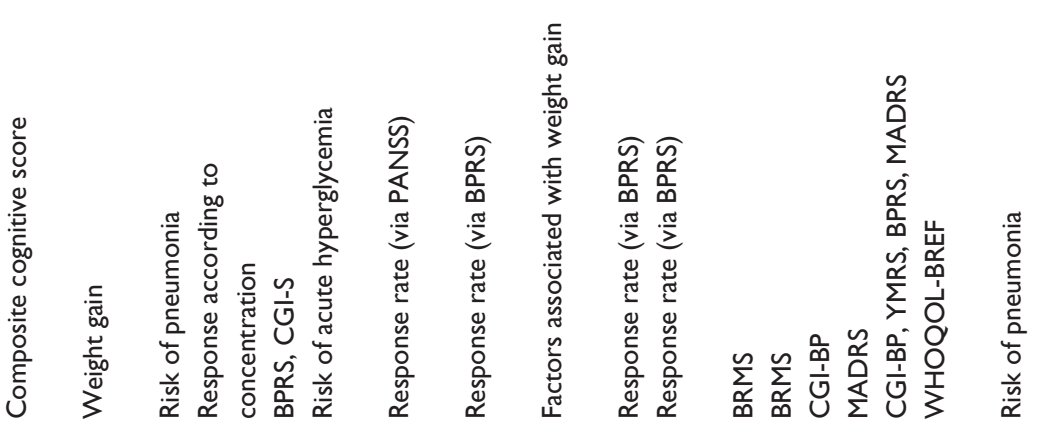

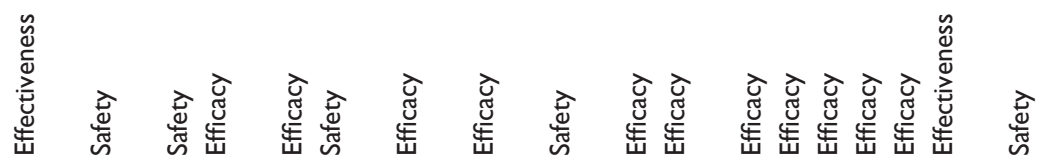

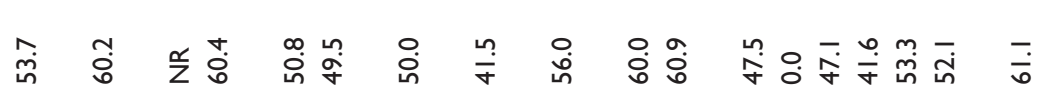

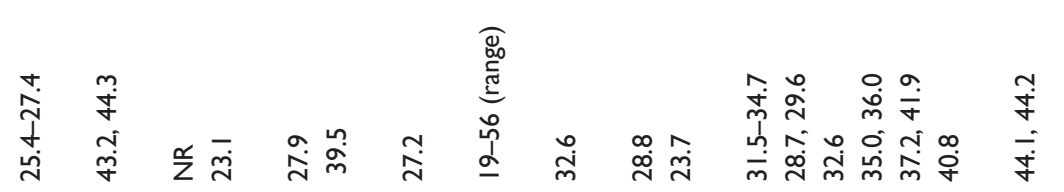

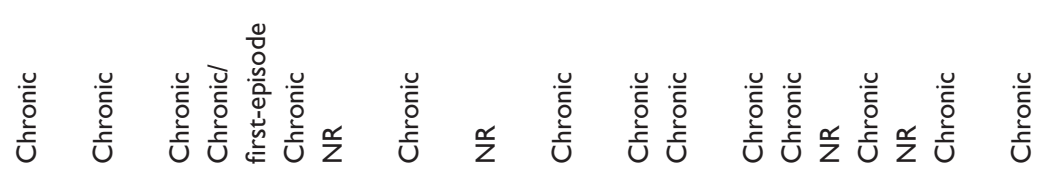

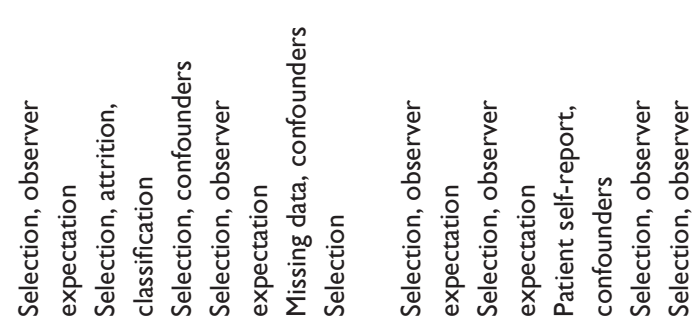

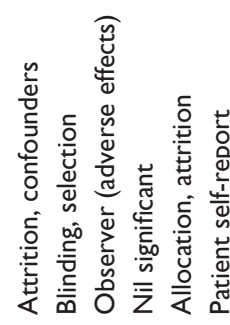

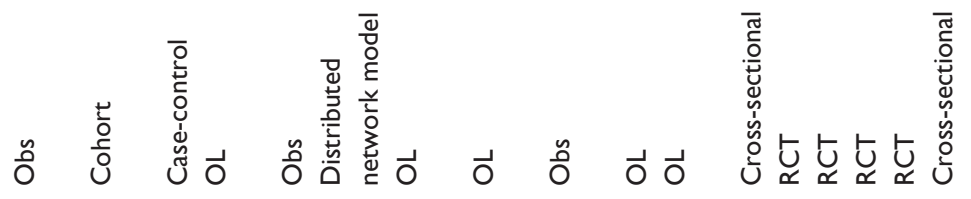

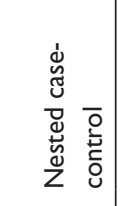

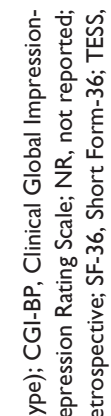

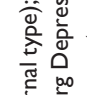

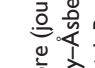

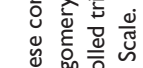

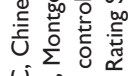

Ư Uू.

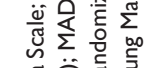

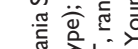

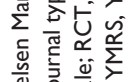

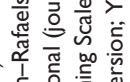

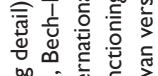

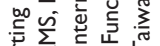




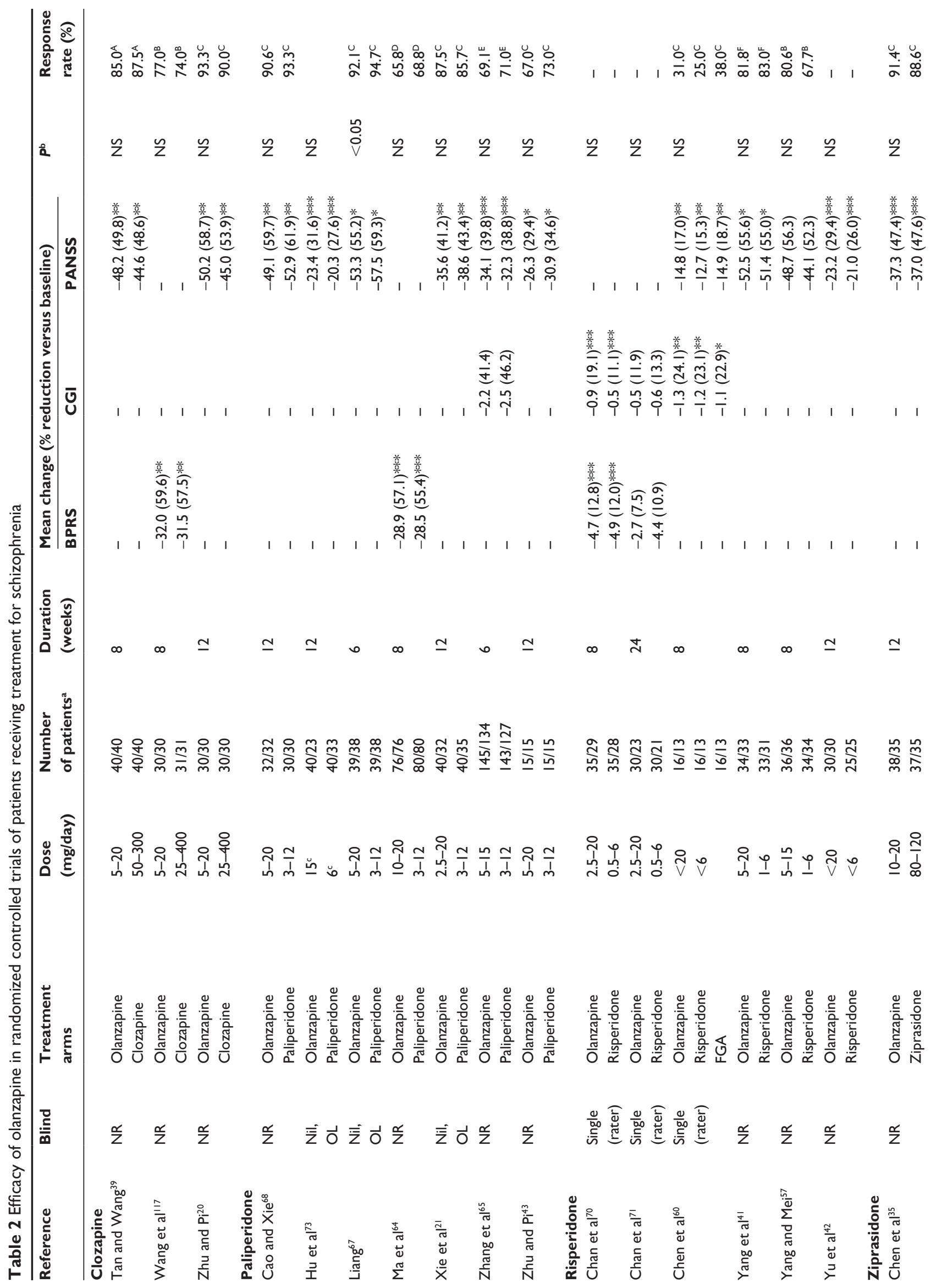




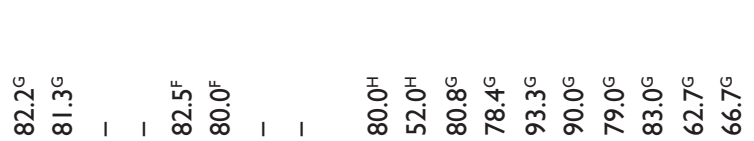

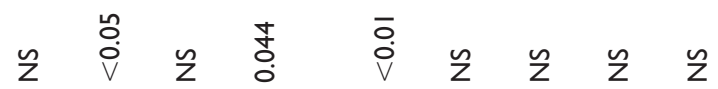

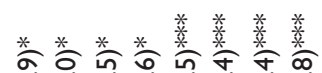

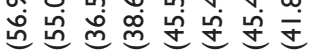
デ

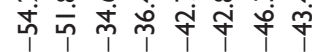
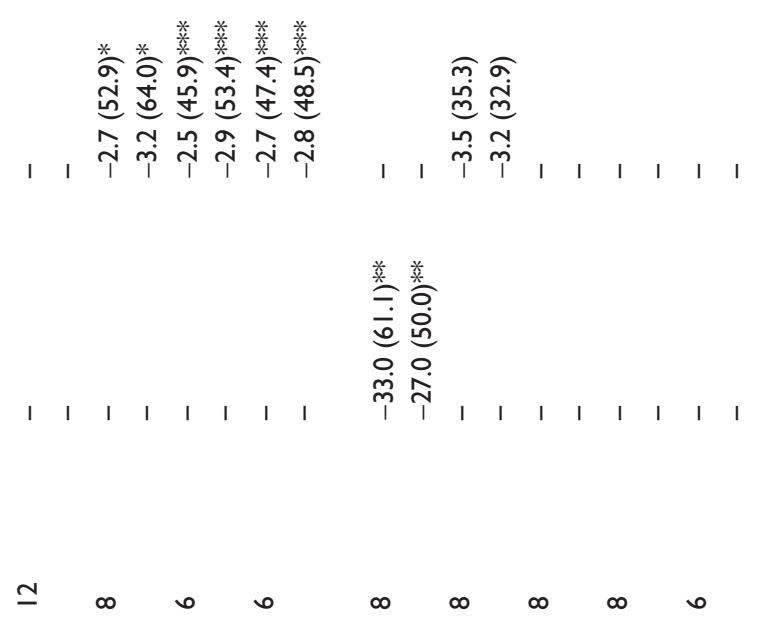

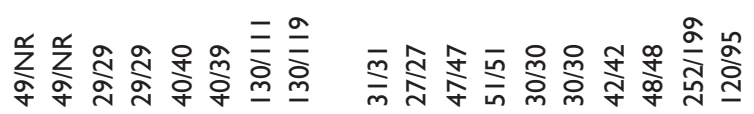

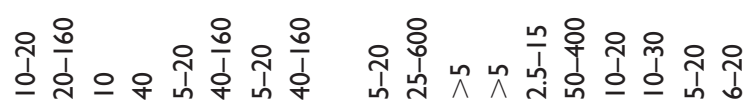

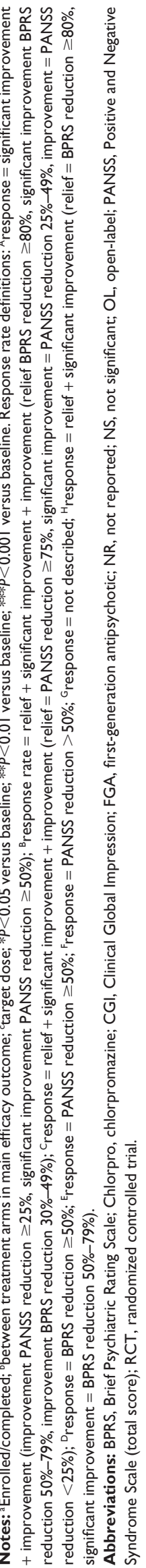

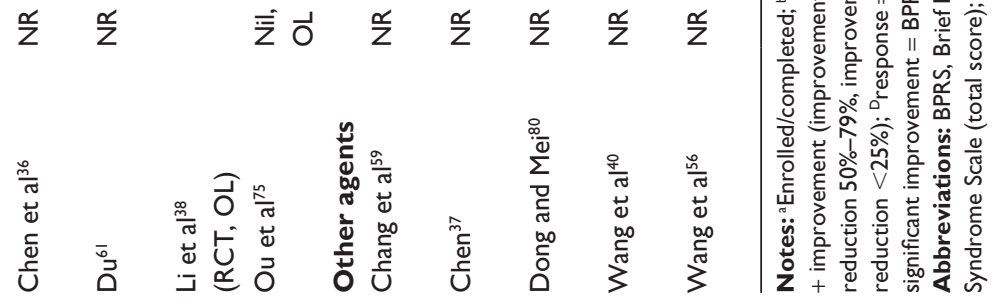


Table 3 Efficacy of olanzapine in noncomparative studies with patients receiving treatment for schizophrenia

\begin{tabular}{|c|c|c|c|c|c|c|c|c|}
\hline \multirow[t]{2}{*}{ Reference } & \multirow[t]{2}{*}{ Design } & \multirow{2}{*}{$\begin{array}{l}\text { Dose } \\
\text { (mg/day) }\end{array}$} & \multirow{2}{*}{$\begin{array}{l}\text { Number of } \\
\text { patients }^{\mathrm{a}}\end{array}$} & \multirow{2}{*}{$\begin{array}{l}\text { Duration } \\
\text { (weeks) }\end{array}$} & \multicolumn{3}{|l|}{ Mean change (\%) } & \multirow{2}{*}{$\begin{array}{l}\text { Response }^{\mathrm{b}} \\
\text { rate }(\%)\end{array}$} \\
\hline & & & & & BPRS & CGI-S & PANSS & \\
\hline Chiu et al ${ }^{119}$ & Open-label & $5-20$ & $42 / 33$ & 8 & - & $-0.3(7.3)^{*}$ & - & - \\
\hline Gao and Chen ${ }^{62}$ & Open-label & $5-15$ & $32 / 32$ & 8 & Symptom reduction ${ }^{\mathrm{e}}$ & - & - & $90.6^{\mathrm{A}}$ \\
\hline Guo et $a^{63}$ & Open-label & $10-20$ & $33 / 33$ & 6 & $-20.9(45.4)^{*}$ & - & $-38.0(45.5)^{*}$ & $84.8^{\mathrm{B}}$ \\
\hline Guo et $\mathrm{al}^{24}$ & Observational & $5-20$ & $\begin{array}{l}149 / 90 \\
1,133 / 674^{d}\end{array}$ & 52 & - & $-0.6(26.1)^{* *}$ & $-5.5(13.0)^{* *}$ & - \\
\hline Guo et $\mathrm{al}^{25}$ & Observational & $5-20$ & $\begin{array}{l}\text { I39/NR } \\
1,133 / 1,029^{d}\end{array}$ & 52 & - & - & $-5.9(14.0)^{* * *}$ & - \\
\hline Li et $\mathrm{al}^{44}$ & Open-label & $5-20$ & $48 / 48$ & 8 & $-19.1(38.9)^{* *}$ & - & $-30.8(34.1)^{* *}$ & $87.5^{C}$ \\
\hline Lu et $\mathrm{a}^{29}$ & Observational & $5-20$ & $\begin{array}{l}494 / 449 \\
1,267 / 954^{d}\end{array}$ & 52 & $-32.0(N R)$ & $-3.0(\mathrm{NR})$ & - & $95.9^{\mathrm{D}}$ \\
\hline Shen and $\mathrm{Li}^{54}$ & Open-label & 5 & $12 / 12$ & 6 & $-21.9(42.7)^{* *}$ & - & $-32.5(57.3)^{* *}$ & $83.4^{\mathrm{E}}$ \\
\hline Shu et $\mathrm{al}^{55}$ & Open-label & $5-20$ & $65 / 62$ & 6 & $-18.8(70.2)^{* *}$ & - & $-35.0(68.9)^{* *}$ & $80.0^{\mathrm{F}}$ \\
\hline Yang et $\mathrm{al}^{121}$ & Open-label & $5-20$ & $75 / 70$ & 6 & $-19.3(71.8)^{* * *}$ & - & $-37.0(69.6)^{* * *}$ & $82.9^{\mathrm{G}}$ \\
\hline Zheng et $\mathrm{a}^{58}$ & Open-label & $5-15$ & $23 / 14$ & 78 & $-34.1(73.0)$ & - & $-29.6(73.3)$ & $73.9^{c, F}$ \\
\hline
\end{tabular}

Notes: ${ }^{a}$ Enrolled/completed; befinition of response varied between studies; ' $r a t e$ after 12 weeks of therapy; ${ }^{d}$ enrolled/completed for whole study population; extent of reduction not quantified; $* P<0.05$ versus baseline; $* * P<0.0$ I versus baseline; $* * * P<0.00$ I versus baseline. Response rate definitions: ${ }^{A}$ response $=$ significant improvement + improvement (significant improvement $=$ BPRS reduction $\geq 30 \%-59 \%$ ); ${ }^{B}$ response $=$ relief + significant improvement (relief $=$ BPRS reduction $\geq 75 \%$, significant improvement $=$ BPRS reduction $50 \%-74 \%$, improvement $=$ BPRS reduction $25 \%-49 \%$; ${ }^{C}$ response $=$ BPRS reduction $\geq 20 \%$; ${ }^{D}$ response $=$ BPRS reduction $\geq 30 \%$; ${ }^{\circ}$ response $=$ significant improvement + improvement (significant improvement $=$ PANSS reduction $\geq 60 \%$, improvement $=$ PANSS reduction $40 \%-59 \%$ ); ${ }^{\text {response }}=$ relief + significant improvement (relief $=$ BPRS reduction $>75 \%$, significant improvement $=$ BPRS reduction $\geq 50 \%$ ); ${ }^{G}$ response $=$ relief + significant improvement + improvement $($ relief $=$ BPRS reduction $\geq 75 \%$, significant improvement $=$ BPRS reduction $50 \%-74 \%$, improvement $=$ BPRS reduction $25 \%-49 \%$ ).

Abbreviations: BPRS, Brief Psychiatric Rating Scale; CGI-S, Clinical Global Impression-Severity; NR, not reported; PANSS, Positive and Negative Syndrome Scale (total score).

Studies with specific safety objectives were made up of the largest number of different study types. The inclusion of nonclinical studies (eg, distributed network models, claims databases) makes it difficult to provide summary statistics on the duration and sample size of these studies.

In reference to olanzapine treatment, most studies used the generic term "olanzapine" $(n=44)$, whereas other studies mentioned the originator brand name of Zyprexa ( $\mathrm{n}=9$ ), the so-called "domestic" generic formulation of olanzapine available in the People's Republic of China (Oulanning,
Jiangsu Haosen Pharmaceutical Ltd, Lianyungang, People's Republic of China, $n=6$ ), or both originator brand and domestic formulations $(n=2)$. Olanzapine was administered as monotherapy in most studies of schizophrenia, except in a small number of prospective observational or retrospective studies. ${ }^{28-31}$ In these studies, combinations with other antipsychotics were specifically allowed or reflected the naturalistic setting of the study design. In studies of bipolar disorder, olanzapine was administered in combination with sodium valproate in one cross-sectional comparative study, ${ }^{32}$ and in

Table 4 Efficacy of olanzapine in comparative studies of patients receiving treatment for bipolar disorder

\begin{tabular}{|c|c|c|c|c|c|c|c|c|c|}
\hline \multirow{2}{*}{$\begin{array}{l}\text { Reference } \\
\text { (design) }\end{array}$} & \multirow{2}{*}{$\begin{array}{l}\text { Treatment } \\
\text { arms }\end{array}$} & \multirow{2}{*}{$\begin{array}{l}\text { Dose } \\
\text { (mg/day) }\end{array}$} & \multirow{2}{*}{$\begin{array}{l}\text { Number of } \\
\text { patients }^{\mathrm{a}}\end{array}$} & \multirow{2}{*}{$\begin{array}{l}\text { Duration } \\
\text { (weeks) }\end{array}$} & \multicolumn{4}{|c|}{ Mean change (\% versus baseline) } & \multirow{2}{*}{$\begin{array}{l}\text { Response }^{t} \\
\text { rate (\%) }\end{array}$} \\
\hline & & & & & BRMS & BPRS & MADRS & YMRS & \\
\hline Jian and $\mathrm{Miao}^{32}$ & Olanzapine & $10-20$ & $40 / 40$ & 8 & $-26.3(94.7)^{* *}$ & \multicolumn{3}{|c|}{ All treatments combined with sodium } & $100.0^{\mathrm{A}}$ \\
\hline (Cross- & Risperidone & $3-6$ & $40 / 40$ & & $-26.6(94.6)^{* *}$ & \multirow{2}{*}{\multicolumn{3}{|c|}{ valproate $0.5-1.8 \mathrm{mg} /$ day }} & $100.0^{\mathrm{A}}$ \\
\hline sectional) & Quetiapine & $400-800$ & $40 / 40$ & & $-29.5(95.7)^{* *}$ & & & & $100.0^{\mathrm{A}}$ \\
\hline Liu et $\mathrm{a}^{45}$ & Olanzapine & $5-20$ & $24 / 24$ & 8 & $-15.7(87.7)^{* *}$ & & & & $87.5^{\mathrm{A}}$ \\
\hline (RCT) & Quetiapine & $200-800$ & $25 / 25$ & & $-16.1(89.0) * *$ & & & & $84.0^{\mathrm{A}}$ \\
\hline Niufan et al ${ }^{46}$ & Olanzapine & $5-20$ & $69 / 63$ & 4 & & $-11.2(N R)^{* * *}$ & $-3.3(\mathrm{NR})^{* * *}$ & $-24.6(N R)^{* * *}$ & $87.0^{\mathrm{B}}$ \\
\hline$(\mathrm{RCT})$ & Lithium & $600-1,800$ & $71 / 56$ & & & $-9.0(N R)^{* * *}$ & $-2.5(\mathrm{NR}) * * *$ & $-20.2(\mathrm{NR})^{* * *}$ & $73.2^{\mathrm{B}}$ \\
\hline Tohen et $\mathrm{al}^{53}$ & Olanzapine & $5-20$ & $343 / 267$ & 6 & & & $-13.8(N R)^{c}$ & -0.67 (NR) & $52.5^{c}$ \\
\hline (RCT) & Placebo & & $171 / 122$ & & & & $-11.7(N R)^{c}$ & +0.32 (NR) & $43.3^{c}$ \\
\hline Yang et al ${ }^{48}$ & Olanzapine & $5-20$ & $28 / 27$ & 4 & & $-9.7(7 \mid .8)^{* *}$ & $-2.7(77.1)$ & $-25.9(77.3)^{* *}$ & $85.7^{\mathrm{B}}$ \\
\hline$(\mathrm{RCT})$ & Lithium & $300-1,800$ & $32 / 31$ & & & $-10.6(73.1)^{* *}$ & $-0.7(18.9)$ & $-24.9(78.8)^{* *}$ & $84.4^{\mathrm{B}}$ \\
\hline
\end{tabular}

Notes: ${ }^{a}$ Enrolled/completed; bdefinition for response varied between studies; cleast-squares mean; $* P<0.05$ versus baseline; $* * P<0.0$ I versus baseline; $* * * P<0.00$ I versus baseline. Response rate definitions: ${ }^{A}$ response $=$ relief rate + significant improvement (relief $=$ BRMS reduction $\geq 75 \%$, significant improvement $=$ BRMS reduction $\geq 50 \%$, improvement $=$ BRMS reduction $\geq 25 \%$; ${ }^{B}$ response $=$ YMRS reduction $\geq 50 \%$; ${ }^{c}$ response $=$ MADRS reduction $\geq 50 \%$.

Abbreviations: BRMS, Bech-Rafaelsen Mania Scale; BPRS, Brief Psychiatric Rating Scale; MADRS, Montgomery-Åsberg Depression Rating Scale; NR, not reported; OL, open-label; RCT, randomized controlled trial; YMRS, Young Mania Rating Scale. 
combination with carbamazepine in one nested case-control noncomparative study. ${ }^{33}$ Olanzapine was administered as monotherapy in all other studies of bipolar disorder.

\section{Patient characteristics}

Most included studies enrolled patients with chronic schizophrenia or bipolar disorder (50 studies); nine studies enrolled patients with first-episode schizophrenia and two studies involved schizophrenia populations with mixed disease stage. The mean age of enrolled patients was approximately 20-40 years in most included studies; three studies enrolled patients older than 60 years and one study enrolled adolescent patients (Table 1). Studies generally enrolled approximately equal numbers of men and women, although a small number of studies examined either sex exclusively. Other study population characteristics, such as hospitalization status or response to previous treatment, were inconsistently reported. In particular, the presence of comorbid conditions (eg, tardive dyskinesia) was reported in relatively few studies.

\section{Efficacy outcomes}

\section{Schizophrenia}

The efficacy of olanzapine in Chinese patients with schizophrenia was assessed in 26 comparative and eleven noncomparative studies. The mean change in the Positive and Negative Syndrome Scale (PANSS) total scores compared with baseline was the most commonly reported symptom outcome measure throughout these comparative and noncomparative studies. ${ }^{34}$

Comparative efficacy studies were all RCTs that involved other antipsychotics, particularly paliperidone $(n=7)$, risperidone $(n=6)$, or ziprasidone ( $n=5$; Table 2 ). Throughout these RCTs, olanzapine treatment was associated with statistically significant reductions in symptom measure scores at end point compared with baseline (Table 2). The relative reduction in PANSS total scores from baseline at end point varied from $17.0 \%$ to $59.9 \%$ (various $P$-values) for olanzapine treatment. From comparative studies that reported PANSS scores, the median change in total PANSS scores was -44.3 and, in more than half (14/22) of these studies, the relative reduction at end point was $>40 \%$. In addition to total PANSS scores, reductions in all PANSS subscores (positive, negative, general psychopathology) were also seen for olanzapine in studies that provided this breakdown. ${ }^{20,21,35-43}$ Response rates in terms of the proportion of patients reaching a specified improvement in symptom score were generally high ( $>75 \%$ in 15 of 20 studies that provided rates). However, a lack of consistent definition for response made it impossible to group or compare these results among studies. Of note in this population, differences between olanzapine and comparator agents in symptom measure score changes at study end point were, in almost all studies, small and not statistically significant $(P>0.05$ for difference between treatment groups, Table 2). One RCT found no statistically significant difference $(P>0.05)$ in change in the PANSS and Clinical Global Impression scores for domestic (Oulanning) and originator brand (Zyprexa) formulations of olanzapine. ${ }^{37}$ There were no apparent differences in efficacy between originator, domestic, or generic olanzapine, with each formulation showing a very similar range of response rates and other efficacy measures throughout the comparative studies.

Noncomparative studies were mostly open-label interventional or observational studies of olanzapine treatment (Table 3). The overall findings from these noncomparative studies were consistent with those of the comparative studies. That is, the noncomparative studies also demonstrated that olanzapine treatment was associated with statistically significant reductions in symptom measure scores at end point compared with baseline (Table 3). Specifically, the relative reduction in PANSS total scores from baseline to end point for olanzapine ranged from $13.0 \%$ to $73.3 \%$. In noncomparative studies that reported PANSS scores, the median change in total PANSS scores was -31.7 and, in approximately half $(5 / 8)$ of these studies, the relative reduction at end point was $>40 \%$. As in the comparative studies, response rates in the noncomparative studies were typically high ( $>75 \%$ in seven of eight studies that provided response rates). Similarly, grouping or comparison of results was not possible due to the variety of definitions for response used. One study reported a correlation between olanzapine blood concentrations and the decrease in scores in the Brief Psychiatric Rating Scale (Pearson correlation $[r]$ at week $8=0.41, P<0.05)$ and Social Disability Screening Schedule ( $r=0.39$ at week $8, P<0.05) .{ }^{44}$ In this study, the response to treatment with olanzapine was greater in patients with a blood concentration $\geq 9 \mathrm{ng} / \mathrm{mL}(95.1 \%)$ than in patients with a blood concentration $<9 \mathrm{ng} / \mathrm{mL}(28.5 \%$ for $P<0.01)$. As with the comparative studies, differences in efficacy outcomes with respect to olanzapine formulation were not apparent between the noncomparative studies.

\section{Bipolar disorder}

Compared with studies related to schizophrenia, considerably fewer studies were conducted to assess the efficacy of olanzapine in patients with bipolar disorder. The efficacy of olanzapine in patients with chronic bipolar disorder (with or without an acute mania episode) was assessed in four RCTs 
and one cross-sectional comparative study (Table 4). ${ }^{32,45-48}$ Studies of bipolar disorder in Chinese populations compared olanzapine with placebo $(n=1)$, lithium $(n=2)$, quetiapine $(n=1)$, and quetiapine or risperidone $(n=1) .{ }^{32,45-48}$ Throughout these comparative studies, various efficacy outcome measures were used, including the Bech-Rafaelsen Mania Scale, ${ }^{49}$ Brief Psychiatric Rating Scale, ${ }^{50}$ Montgomery-Åsberg Depression Rating Scale (MADRS), ${ }^{51}$ and the Young Mania Rating Scale (YMRS). ${ }^{52}$

In terms of managing symptoms of mania, a placebocontrolled RCT by Tohen et al, in which most participants were of East Asian ethnicity, found that patients treated with olanzapine had a greater change in the secondary outcome measures related to mania, including the Clinical Global Impression and YMRS, compared with patients treated with placebo. ${ }^{53}$ In the other comparative studies, significant improvements in symptom measures from baseline were observed in patients treated with olanzapine (Table 4). The response rate in the active comparator studies varied from $85.7 \%$ to $100.0 \%$ for olanzapine-treated patients, although the definition of response was not consistent throughout these studies (Table 4). ${ }^{32,45,46,48}$ There were no significant differences $(P>0.05)$ between olanzapine and other antipsychotics with regard to the change in efficacy outcome measures for mania at end point. Two RCTs compared olanzapine with lithium as a control. ${ }^{46,48}$ In terms of symptom measures, there were no statistically significant differences between olanzapine and lithium in these studies. ${ }^{46,48}$ However, in one trial, the response rate $(\geq 50 \%$ increase in YMRS) with olanzapine (87.0\%) was significantly greater than that observed with lithium $(73.2 \%, P=0.035) .{ }^{46}$

In terms of managing depressive symptoms, the study by Tohen et al found that olanzapine was significantly more effective than placebo based on the primary outcome measure of change from baseline to end point in MADRS $(-13.82$ versus $-11.67, P=0.018$ ) as well as the mean change in the 17-item Hamilton Depression Rating Scale $(-11.05$ versus $-8.84, P=0.002) .{ }^{53}$ Response, defined as a $\geq 50 \%$ reduction in MADRS at end point, was also significantly greater in patients treated with olanzapine than in those treated with placebo (52.5\% versus $43.3 \%$ for placebo, $P=0.0498) .{ }^{53} \mathrm{On}$ the other hand, patients treated with either olanzapine or lithium had similar changes in MADRS score in two other separate RCTs $(P>0.05$, Table 4$) .{ }^{46,48}$

\section{Effectiveness outcomes}

Compared with studies that reported efficacy, fewer studies reported effectiveness outcomes, which related to treatment discontinuation, quality of life, and cognitive function, primarily in patients with schizophrenia. In one study, quality of life was assessed in a mixed population of patients with either bipolar disorder or schizophrenia. ${ }^{26}$

\section{Treatment discontinuation}

Data on treatment discontinuation were provided for Chinese patients receiving olanzapine or other antipsychotic agents in a cohort study and in an observational study, in which both populations received maintenance therapy for 12 months. ${ }^{22,24}$ For olanzapine, 12-month total discontinuation rates of $39.6 \%$ and $44.0 \%$ were reported in these studies. ${ }^{22,24}$ The time to discontinuation was reported as 6.0 months $(25 \%$ percentile of Kaplan-Meier estimate, 95\% confidence interval 3.1-7.9 months) in one study and 9.1 months (mean, 95\% confidence interval 8.5-9.8 months) in the other study. ${ }^{22,24}$ In both study populations, the 12-month total discontinuation rate and time to discontinuation for olanzapine were not statistically significantly different from other antipsychotics (Figure 2). ${ }^{22,24}$ The most common cause of discontinuation in both studies was relapse, although tolerability issues and loss to follow-up were reported as the cause of discontinuation for a number of patients. ${ }^{22,24}$ Discontinuation rates due to specific causes (eg, intolerance, relapse) were also not significantly different between treatment groups in both studies. ${ }^{22,24}$

\section{Quality of life}

Quality of life was assessed in two RCTs, one cohort study, one cross-sectional study, and one observational study (Table 5). ${ }^{20,21,25-27}$ In two studies, olanzapine and six other antipsychotic agents were associated with improvements in various domains of the Short Form-36 over a 12-month period in patients with schizophrenia. ${ }^{22,24}$ Improvements associated with olanzapine were particularly seen in the role physical and role emotional domains of the Short Form-36 (Figure 3). ${ }^{25,27}$ In one study, post-hoc tests found that olanzapine-treated and quetiapine-treated patients improved significantly more than chlorpromazine-treated patients. ${ }^{24}$

\section{Neurocognitive function}

Assessment of neurocognitive function was the primary objective of two studies. ${ }^{19,23}$ In a placebo-controlled RCT of 129 patients with first-episode schizophrenia, patients treated with olanzapine experienced significantly improved short-term memory, immediate memory, and memory quotient as assessed by the Wechsler Memory Scale (Fourth Edition) over a 12-week period compared with placebo $(\mathrm{n}=132, P<0.01) .{ }^{19}$ In one naturalistic study, 698 analyzable patients with early-stage schizophrenia received olanzapine, 


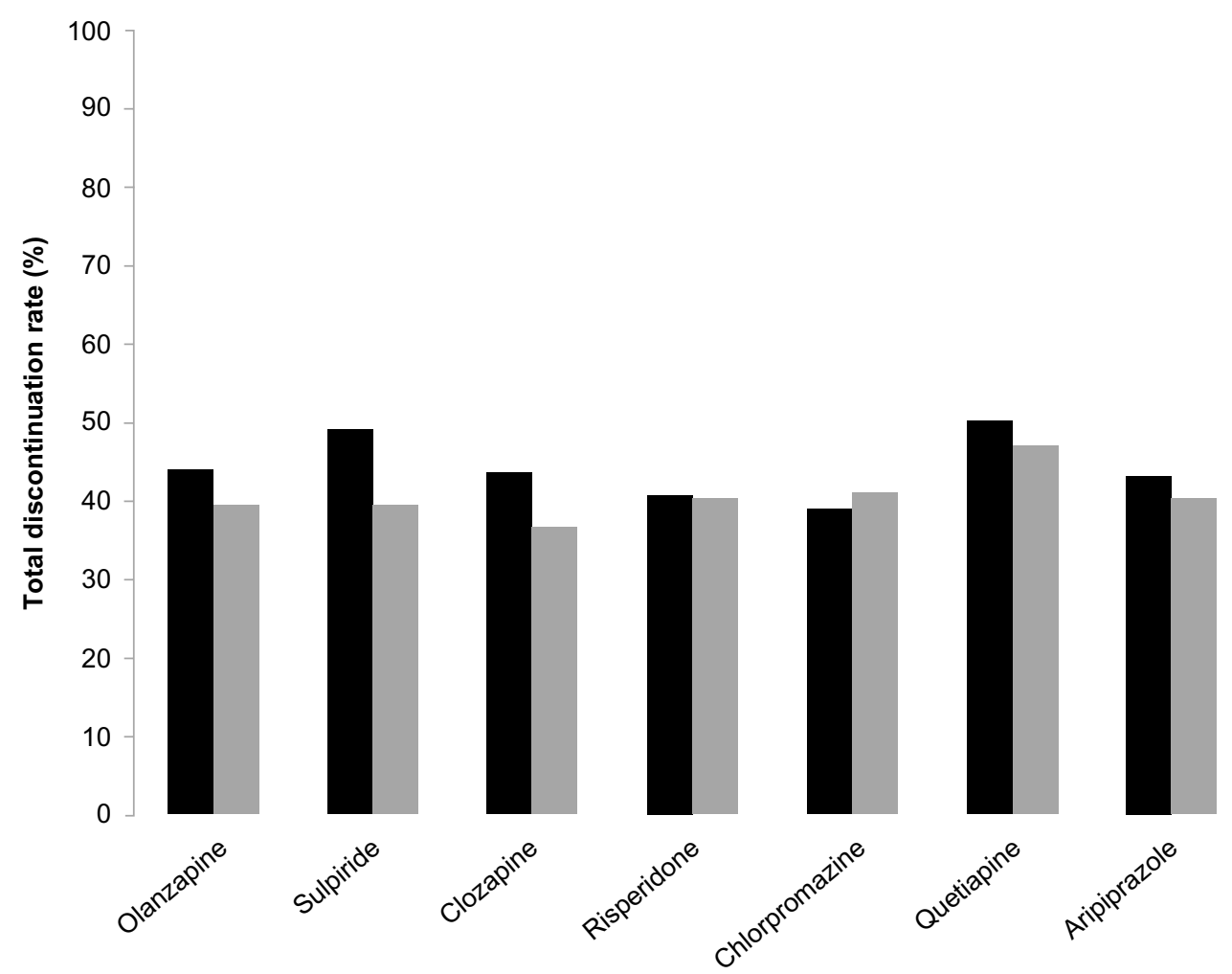

Figure 2 Discontinuation rates in long-term (12-month) maintenance studies.

Notes: Dark bar represents data from Fang et $\mathrm{a}^{22}$ and gray bar represents data from Guo et al. ${ }^{24}$

Table 5 Characteristics of quality of life and functioning studies in schizophrenia and bipolar disorder

\begin{tabular}{|c|c|c|c|c|c|}
\hline $\begin{array}{l}\text { Reference } \\
\text { (design) }\end{array}$ & $\begin{array}{l}\text { Treatment } \\
\text { arms }\end{array}$ & $\begin{array}{l}\text { Number of } \\
\text { patients }^{\mathrm{a}}\end{array}$ & $\begin{array}{l}\text { Duration } \\
\text { (weeks) }\end{array}$ & $\begin{array}{l}\text { Assessment } \\
\text { measure(s) }\end{array}$ & Results for olanzapine-treated patients \\
\hline $\begin{array}{l}\text { Fang et } \mathrm{al}^{27} \\
\text { (Observational) }\end{array}$ & $\begin{array}{l}\text { Olanzapine } \\
\text { Chlorpromazine } \\
\text { Sulpiride } \\
\text { Clozapine } \\
\text { Risperidone } \\
\text { Quetiapine } \\
\text { Aripiprazole }\end{array}$ & $\begin{array}{l}158 / 111 \\
174 / 120 \\
185 / 129 \\
193 / 135 \\
221 / 155 \\
151 / 99 \\
133 / 99\end{array}$ & 52 & SF-36 & $\begin{array}{l}\text { QOL improved in all domains; greatest improvements } \\
\text { in role physical and role emotional domains }\end{array}$ \\
\hline $\begin{array}{l}\text { Guo et al }{ }^{25} \\
\text { (Observational) }\end{array}$ & $\begin{array}{l}\text { Olanzapine } \\
\text { Chlorpromazine } \\
\text { Sulpiride } \\
\text { Clozapine } \\
\text { Risperidone } \\
\text { Quetiapine } \\
\text { Aripiprazole }\end{array}$ & $\begin{array}{l}139 / 86 \\
151 / 90 \\
150 / 9 \mid \\
158 / 10 \mid \\
185 / 111 \\
125 / 73 \\
121 / 73\end{array}$ & 52 & $\begin{array}{l}\text { SF-36 } \\
\text { GAS } \\
\text { ADL }\end{array}$ & $\begin{array}{l}\text { At } 12 \text { months, significant improvements in all eight } \\
\text { SF- } 36 \text { domains, GAS and ADL (all } P \leq 0.00 \text { I); greater } \\
\text { improvement in the SF- } 36 \text { role physical score and } \\
\text { GAS score than chlorpromazine (all } P=0.002 \text { ) }\end{array}$ \\
\hline $\begin{array}{l}\text { Xie et } \mathrm{a}^{21} \\
(\mathrm{OL}) \\
\text { Yen et a } \mathrm{a}^{26} \\
\text { (Cross-sectional) }\end{array}$ & $\begin{array}{l}\text { Olanzapine } \\
\text { Paliperidone } \\
\text { Olanzapine } \\
\text { Risperidone } \\
\text { Clozapine } \\
\text { Other }\end{array}$ & $\begin{array}{l}40 / 32 \\
40 / 35 \\
N R / 27 \\
N R / 55 \\
N R / 8 \\
N R / 7\end{array}$ & 12 & $\begin{array}{l}\text { PSP } \\
\text { WHOQOL- } \\
\text { BREF-Taiwan }\end{array}$ & $\begin{array}{l}\text { Scores increased from baseline to week } 12 \\
(31.47 \pm 7.66 \text { to } 60.13 \pm 12.54, P<0.0 \text { I versus baseline) } \\
\text { Psychological domain: higher scores for olanzapine } \\
\text { than risperidone or no atypical antipsychotic }(P<0.01) \\
\text { Social relationship domain: higher scores for } \\
\text { olanzapine than no atypical antipsychotic }(P<0.05)\end{array}$ \\
\hline $\begin{array}{l}\text { Zhu and } \mathrm{Pi}^{20} \\
(\mathrm{RCT})\end{array}$ & $\begin{array}{l}\text { Olanzapine } \\
\text { Clozapine }\end{array}$ & $\begin{array}{l}30 / 30 \\
30 / 30\end{array}$ & 12 & GQOLI & $\begin{array}{l}\text { Total GQOLI, physical health, psychological health, } \\
\text { and social function: higher scores for olanzapine than } \\
\text { clozapine }(P<0.01)\end{array}$ \\
\hline
\end{tabular}

Note: ${ }^{\mathrm{a} E n r o l l e d / c o m p l e t e d . ~}$

Abbreviations: ADL, Activities of Daily Living scale: GAS, Global Assessment Scale; GQOLI, General Quality of Life Inventory; NR, not reported; OL, open-label; PSP, Personal and Social Performance Scale; QOL, Quality of Life; SF-36, Short Form-36; WHOQOL-BREF-Taiwan, World Health Organization Questionnaire on Quality of Life: Short Form (Taiwanese version); RCT, randomized controlled trial. 


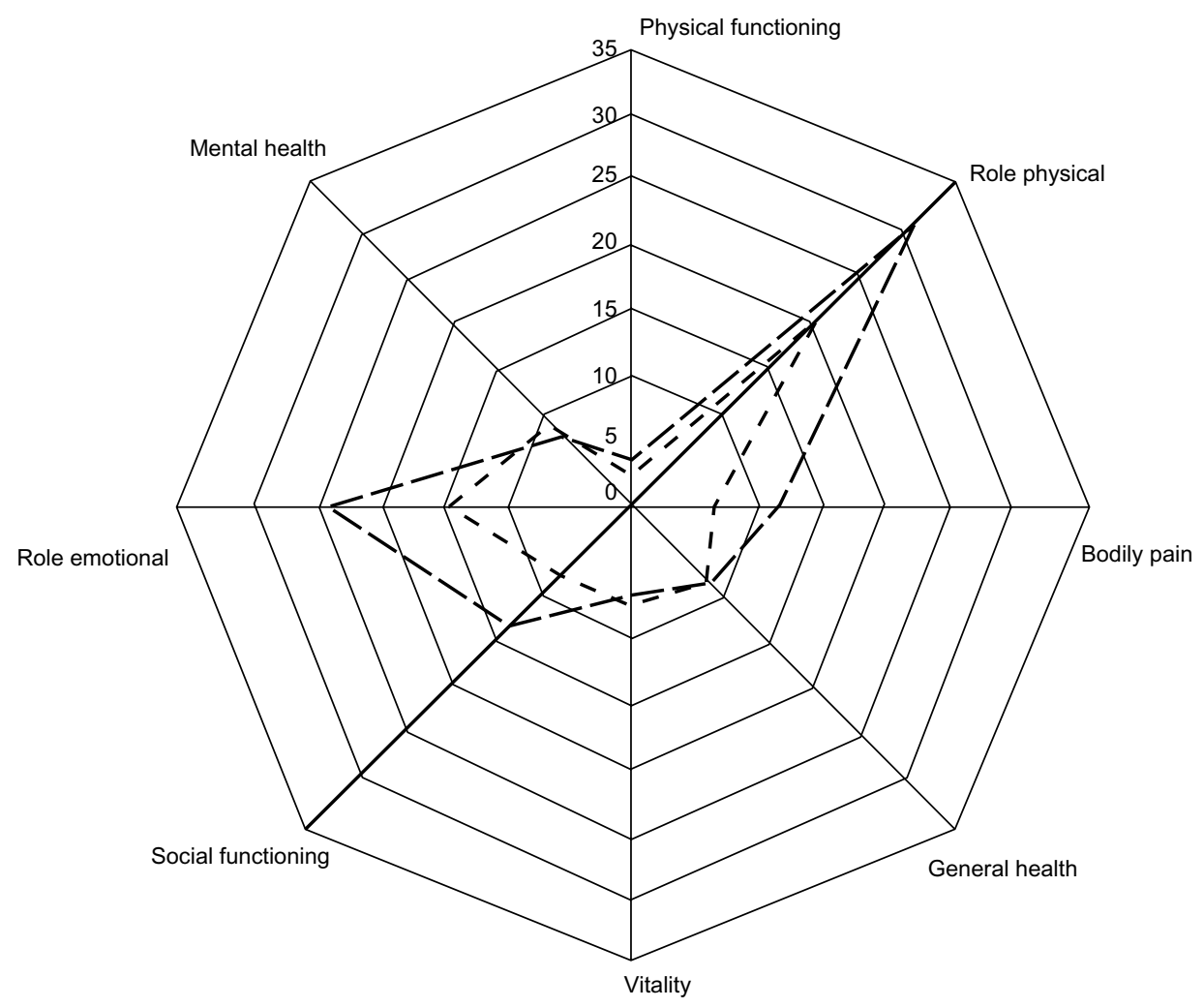

Figure 3 Mean change in Short Form-36 domain scores from baseline after 12 months of treatment with olanzapine in patients with schizophrenia reported in two quality of life studies.

Notes: Long dashed lines represent data from Guo et al; ${ }^{25}$ short dashed lines represent data from Fang et al. ${ }^{27}$

chlorpromazine, sulpiride, clozapine, risperidone, quetiapine, or aripiprazole monotherapy. ${ }^{23}$ Neurocognitive tests including the Wechsler Memory Scale-Revised Visual Reproduction Test, Wechsler Adult Intelligence ScaleRevised Digit Symbol Test, Computerized Wisconsin Card Sorting Test (128-card version), Trail Making Tests, and the Wechsler Adult Intelligence Scale-Revised Digit Span Test assessed aspects such as attention and memory, and was administered at baseline, 6 and 12 months. From these tests, a cognitive composite effect size $(z)$ score was calculated based on average domain scores that measured processing speed, attention/working memory, executive functioning, and visual memory. Overall, mild to moderate neurocognitive improvements were seen in the olanzapine group $(z=0.69)$ and the other treatment groups $(z=0.32-0.64) .{ }^{23}$

\section{Safety and tolerability outcomes}

Safety and tolerability data were reported in most studies, including detailed information in 22 studies that had a specific safety or tolerability objective (Table 6).

The most common adverse events observed in patients treated with olanzapine in the studies that mainly reported efficacy outcomes included drowsiness or sedation, weight gain, dry mouth, and dizziness. ${ }^{21,32,41,43,44,46,53-65}$ Of patients treated with olanzapine, drowsiness or sedation was noted in $2.5 \%-69.0 \% ;^{35,66}$ weight gain (generally defined as an increase in weight $\geq 7 \%$ from baseline) was noted in $26.2 \%-53.1 \% ;{ }^{36,56}$ dry mouth was noted in $2.6 \%-47.2 \% ;^{22,67}$ and dizziness was noted in 3.3\%-50.0\%. ${ }^{60,68}$ Many of these common adverse events were also noted in patients treated with other antipsychotic agents, although the incidence was either not reported or varied widely between different studies. On the other hand, the incidence of extrapyramidal symptoms among patients treated with olanzapine was generally low compared with other antipsychotics. ${ }^{38,41,56,65}$ Extrapyramidal symptoms were noted in $0.0 \%-23.2 \%$ of patients treated with olanzapine..$^{22,32}$ In the efficacy studies, the most commonly observed laboratory abnormalities during olanzapine treatment were transient increases in liver enzymes without clinical significance, glucose metabolism parameters, and lipid levels. . $^{36,43,56,64,65}$ Similar laboratory changes were also noted in patients treated with other antipsychotic agents throughout the efficacy studies, although the prevalence of these changes varied widely.

In the studies that included a specific safety or tolerability objective, weight gain, changes in metabolic parameters, 
Table 6 Characteristics of studies including a specific safety or tolerability objective in studies of schizophrenia or bipolar disorder

\begin{tabular}{lllll}
\hline $\begin{array}{l}\text { Reference } \\
\text { (design) }\end{array}$ & $\begin{array}{l}\text { Treatment } \\
\text { arms }\end{array}$ & $\begin{array}{l}\text { Number of } \\
\text { patients }^{\mathbf{a}}\end{array}$ & $\begin{array}{l}\text { Duration } \\
\text { (weeks) }\end{array}$ & $\begin{array}{l}\text { Primary or specified } \\
\text { safety objective }\end{array}$ \\
\hline $\begin{array}{l}\text { Ang et al }{ }^{69} \\
\text { (observational, }\end{array}$ & Olanzapine & $330 / 325$ & 26 & $\begin{array}{l}\text { Identify factors associated } \\
\text { with weight gain during }\end{array}$ \\
post hoc) & & & olanzapine therapy
\end{tabular}

Outcomes

Factors associated with weight gain: preoccupied with food thoughts, evening snacks, excessive food consumed to feel full, red meat, comfortably full sensation when finished eating, amount of daily continuous walking, location of meals, social activity level, meal regularity, sex

\begin{tabular}{|c|c|c|c|c|}
\hline $\begin{array}{l}\text { Chan et } \mathrm{al}^{70} \\
(\mathrm{RCT})\end{array}$ & $\begin{array}{l}\text { Olanzapine } \\
\text { Risperidone }\end{array}$ & $\begin{array}{l}35 / 29 \\
35 / 28\end{array}$ & 8 & $\begin{array}{l}\text { Compare effects in } \\
\text { patients with intolerable } \\
\text { EPS receiving an FGA }\end{array}$ \\
\hline $\begin{array}{l}\text { Chan et } \mathrm{al}^{71} \\
\text { (RCT) }\end{array}$ & $\begin{array}{l}\text { Olanzapine } \\
\text { Risperidone }\end{array}$ & $\begin{array}{l}30 / 23 \\
30 / 21\end{array}$ & 24 & $\begin{array}{l}\text { Compare effects in } \\
\text { patients with tardive } \\
\text { dyskinesia receiving } \\
\text { an FGA }\end{array}$ \\
\hline $\begin{array}{l}\text { Chen et } \mathrm{al}^{35} \\
\text { (RCT) }\end{array}$ & $\begin{array}{l}\text { Olanzapine } \\
\text { Ziprasidone }\end{array}$ & $\begin{array}{l}35 / 32 \\
35 / 33\end{array}$ & 12 & $\begin{array}{l}\text { Explore the impact on } \\
\text { glucose/lipid metabolism of } \\
\text { olanzapine and ziprasidone } \\
\text { in older patients }\end{array}$ \\
\hline $\begin{array}{l}\text { Chen }^{37} \\
(\mathrm{RCT})\end{array}$ & $\begin{array}{l}\text { Oulanning (generic) } \\
\text { Zyprexa }^{\circledR} \text { (originator } \\
\text { brand) }\end{array}$ & $\begin{array}{l}51 / 51 \\
47 / 47\end{array}$ & 8 & $\begin{array}{l}\text { Compare glucose/lipid } \\
\text { metabolism of generic } \\
\text { olanzapine and Zyprexa }\end{array}$ \\
\hline $\begin{array}{l}\text { Chen et } \mathrm{al}^{72} \\
\text { (case-control) }\end{array}$ & $\begin{array}{l}\text { Olanzapine } \\
\text { Control }\end{array}$ & $\begin{array}{l}66 / 66 \\
119 / 119\end{array}$ & - & $\begin{array}{l}\text { Explore association } \\
\text { between weight gain } \\
\text { and ghrelin levels with } \\
\text { olanzapine }\end{array}$ \\
\hline
\end{tabular}

\begin{tabular}{|c|c|c|c|c|}
\hline $\begin{array}{l}\text { Chiu et al }{ }^{119} \\
\text { (open-label) }\end{array}$ & Olanzapine & $42 / 33$ & 8 & $\begin{array}{l}\text { Investigate the continuous } \\
\text { changes of insulin secretion } \\
\text { and other metabolic } \\
\text { indices after olanzapine } \\
\text { therapy }\end{array}$ \\
\hline \multirow{4}{*}{$\begin{array}{l}\text { Guo et } \text { al }^{24} \\
\text { (observational) }\end{array}$} & Olanzapine & $149 / 90$ & \multirow[t]{4}{*}{52} & Compare the safety of \\
\hline & Chlorpromazine & $169 / 99$ & & seven antipsychotic agents \\
\hline & Sulpiride & $162 / 98$ & & for maintenance therapy \\
\hline & Clozapine & $177 / 1 \mid 2$ & & in schizophrenia \\
\hline
\end{tabular}
Incidence of concomitant anticholinergic drug use higher for risperidone than olanzapine (I 4/35 versus 4/35, OR 5.17 (I.49-17.88; $P=0.013$ ); no significant difference in EPS

Significant reduction in total AIMS for olanzapine $(-6.2 \pm 8.0)$ and risperidone $(-7.4 \pm 6.9)$; weight gain for risperidone and olanzapine $4.9 \pm 7.1 \mathrm{~kg}$ and $4.6 \pm 6.0 \mathrm{~kg}$, respectively FBG, TC, TG, HDL-C, LDL-C, and BMI did not change significantly in ziprasidone group but increased in olanzapine group $(P<0.001$ betweengroup)

Mean blood glucose, TC, and TG all significantly higher at study end from baseline for both groups $(P<0.05)$

Olanzapine-treated patients had larger waist size, WHR than control; patients with weight gain had lowest serum ghrelin levels $(822.3 \pm 253$. I pg/mL

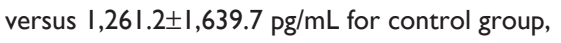
$P=0.01$ )

At end point, olanzapine-treated patients had significant increases in body weight, TG, TC, and LDL-C; insulin secretion initially decreased, returned to baseline, then significantly increased at study end point

Olanzapine associated with a higher incidence of weight gain than other agents $(P<0.005)$ but a relatively low incidence of EPS and anticholinergic effects; incidence of drowsiness (4I.6\%) was higher than other agents except clozapine (47.5\%)

12 Compare effects on metabolic profile, weight, insulin resistance, and beta-cell function

\begin{tabular}{|c|c|c|c|c|}
\hline \multirow[t]{2}{*}{$\begin{array}{l}\text { Huang et al }{ }^{120} \\
\text { (cohort) }\end{array}$} & $\begin{array}{l}\text { Olanzapine } \\
\text { Clozapine }\end{array}$ & $\begin{array}{l}79 / 79 \\
275 / 275\end{array}$ & & $\begin{array}{l}\text { Examine association } \\
\text { between TNF- } \alpha-308\end{array}$ \\
\hline & Risperidone & $146 / 146$ & & $\begin{array}{l}\mathrm{G}>\mathrm{A} \text { polymorphism } \\
\text { and weight gain }\end{array}$ \\
\hline $\begin{array}{l}\text { Kuo et al }{ }^{28} \\
\text { (case-control) }\end{array}$ & Nationwide cohort & 33,024 & - & $\begin{array}{l}\text { Assess the association } \\
\text { between SGA and risk } \\
\text { of pneumonia requiring } \\
\text { hospitalization }\end{array}$ \\
\hline
\end{tabular}

Weight, BMI, mean subcutaneous fat, and WHR increased significantly in both treatment groups but more so for olanzapine (mean change in weight after 12 weeks, $4.66 \mathrm{~kg}, P<0.00 \mathrm{I}$ versus baseline); mean FBG, mean LDL-C increased significantly in the olanzapine group; fasting TC and TG increased significantly in both groups $(P<0.05$ for paliperidone, $P<0.0$ I for olanzapine versus baseline)

Study found no significant association between body weight gain and TNF- $\alpha-308 \mathrm{G}>\mathrm{A}$ polymorphism

Adjusted RR for pneumonia (current use): clozapine 3.18 , olanzapine 1.83, quetiapine 1.63 , zotepine I.48, risperidone I.32, amisulpride I.I4; dose-dependent increase in risk for clozapine only 
Table 6 (Continued)

\begin{tabular}{|c|c|c|c|c|c|}
\hline $\begin{array}{l}\text { Reference } \\
\text { (design) }\end{array}$ & $\begin{array}{l}\text { Treatment } \\
\text { arms }\end{array}$ & $\begin{array}{l}\text { Number of } \\
\text { patients }^{\mathrm{a}}\end{array}$ & $\begin{array}{l}\text { Duration } \\
\text { (weeks) }\end{array}$ & $\begin{array}{l}\text { Primary or specified } \\
\text { safety objective }\end{array}$ & Outcomes \\
\hline $\begin{array}{l}\text { Lee and Leung }^{74} \\
\text { (cross- } \\
\text { sectional) }\end{array}$ & $\begin{array}{l}\text { Olanzapine } \\
\text { Risperidone }\end{array}$ & $\begin{array}{l}45 / 45 \\
30 / 30\end{array}$ & - & $\begin{array}{l}\text { Determine the metabolic } \\
\text { outcomes in patients } \\
\text { treated with olanzapine } \\
\text { or risperidone }\end{array}$ & $\begin{array}{l}\text { Mean weight gain for olanzapine }(7.0 \pm 6.3 \mathrm{~kg}) \\
\text { greater than for risperidone }(3.1 \pm 6.2 \mathrm{~kg}) ; \\
\text { dyslipidemia found in } 50 \% \text { of olanzapine group } \\
\text { and } 12.5 \% \text { of risperidone group; no statistically } \\
\text { significant difference between groups for } \\
\text { metabolic syndrome }\end{array}$ \\
\hline $\begin{array}{l}\text { Lee et } \mathrm{al}^{66} \\
\text { (cohort) }\end{array}$ & $\begin{array}{l}\text { Olanzapine } \\
\text { Risperidone }\end{array}$ & $\begin{array}{l}28 / 28 \\
28 / 28\end{array}$ & $\begin{array}{l}103.5 \\
93.2\end{array}$ & $\begin{array}{l}\text { Compare the effects of } \\
\text { olanzapine and risperidone } \\
\text { on weight gain in matched } \\
\text { pairs }\end{array}$ & $\begin{array}{l}\text { Weight change (mean } \pm \text { SD) for olanzapine group } \\
(8.34 \pm 5.97 \mathrm{~kg}) \text { greater than for risperidone } \\
\text { group }(2.74 \pm 8.09 \mathrm{~kg}, P<0.005 \text { for difference } \\
\text { between groups); mean weight gain was negatively } \\
\text { associated with baseline body weight and } \\
\text { pretreatment BMI for both groups }\end{array}$ \\
\hline $\begin{array}{l}\text { Ou et } \mathrm{al}^{75} \\
\text { (RCT) }\end{array}$ & $\begin{array}{l}\text { Olanzapine } \\
\text { Ziprasidone }\end{array}$ & $\begin{array}{l}130 / 111 \\
130 / 119\end{array}$ & 6 & $\begin{array}{l}\text { Compare metabolic } \\
\text { effects in first-episode } \\
\text { schizophrenia }\end{array}$ & $\begin{array}{l}\text { Weight change (mean } \pm \text { SD) for olanzapine } \\
(4.22 \pm 3.49 \mathrm{~kg}) \text { greater than for ziprasidone } \\
(-0.84 \pm 2.04 \mathrm{~kg}, P<0.00 \text { I for difference between } \\
\text { groups); significant increases in } \mathrm{FBG} \text {, insulin, TC, } \\
\text { LDL-C, HDL-C, and TG at week } 6(P<0.05)\end{array}$ \\
\hline $\begin{array}{l}\text { Pratt et } \mathrm{al}^{76} \\
\text { (distributed } \\
\text { network model) }\end{array}$ & Model & $10^{6}$ simulated & - & $\begin{array}{l}\text { Investigate the risk of } \\
\text { acute hyperglycemia with } \\
\text { antipsychotic use }\end{array}$ & $\begin{array}{l}\text { Olanzapine initiation associated with significantly } \\
\text { increased risk of insulin initiation in USA and } \\
\text { Swedish databases but not in Taiwanese database } \\
\text { (trend toward increased risk) }\end{array}$ \\
\hline $\begin{array}{l}\text { Su et } \text { al }^{77} \\
\text { (observational, } \\
\text { crossover) }\end{array}$ & $\begin{array}{l}\text { Olanzapine } \\
\text { Risperidone }\end{array}$ & $\begin{array}{l}15 / 15 \\
15 / 15\end{array}$ & 12 & $\begin{array}{l}\text { Compare changes in } \\
\text { glucose/lipids and body } \\
\text { weight in patients switching } \\
\text { from olanzapine to } \\
\text { risperidone or vice versa }\end{array}$ & $\begin{array}{l}\text { Olanzapine associated with greater mean } \\
\text { body weight }(P=0.00 \mathrm{I}) \text {, BMI }(P=0.0 \mathrm{I} 5) \text {, and } \\
\text { TG }(P=0.00 \mathrm{I}) \text {, compared with risperidone; no } \\
\text { significant difference in FBG }(P=0.39) \text { and LDL-C } \\
(P=0.72) \text { between groups }\end{array}$ \\
\hline $\begin{array}{l}\text { Treuer et } \mathrm{al}^{30} \\
\text { (observational) }\end{array}$ & Olanzapine & 380 & 26 & $\begin{array}{l}\text { Examine clinical, eating and } \\
\text { lifestyle factors associated } \\
\text { with weight gain when } \\
\text { initiating/switching to } \\
\text { olanzapine }\end{array}$ & $\begin{array}{l}\text { Weight gain (mean, } 95 \% \mathrm{Cl} \text { ) after } 6 \text { months: } \\
\text { People's Republic of China }(5.0 \mathrm{l} \mathrm{kg}, 4.36-5.65 \mathrm{~kg}) \text {, } \\
\text { Taiwan ( } 3.52 \mathrm{~kg}, 2.0 \mathrm{I}-5.03 \mathrm{~kg}) \text {; factors associated } \\
\text { with weight gain: country, housing conditions, } \\
\text { stronger appetite, excessive amount of food } \\
\text { needed to feel full, eating until uncomfortably } \\
\text { full, thoughts preoccupied with food, meal } \\
\text { location, increased meal frequency, evening snack } \\
\text { consumption, lower amount of vigorous exercise }\end{array}$ \\
\hline $\begin{array}{l}\text { Wang et al }{ }^{1 / 8} \\
\text { (cohort) }\end{array}$ & $\begin{array}{l}\text { Olanzapine } \\
\text { Amisulpride }\end{array}$ & $\begin{array}{l}\text { I8/NR } \\
\text { I5/NR }\end{array}$ & 12 & $\begin{array}{l}\text { Monitor heart rate } \\
\text { variability in patients } \\
\text { switching to olanzapine } \\
\text { or amisulpride due } \\
\text { to tardive dyskinesia }\end{array}$ & $\begin{array}{l}\text { Amisulpride had a more vagotonic effect: } \\
\text { statistically significant increases in the mean, } \\
\text { variance and high-frequency power of RR } \\
\text { intervals with amisulpride, but not olanzapine }\end{array}$ \\
\hline $\begin{array}{l}\text { Wu et } \mathrm{al}^{78} \\
(\mathrm{RCT})\end{array}$ & $\begin{array}{l}\text { Olanzapine } \\
\text { Clozapine } \\
\text { Risperidone } \\
\text { Sulpiride }\end{array}$ & $\begin{array}{l}N R / 24 \\
N R / 30 \\
N R / 29 \\
N R / 29\end{array}$ & 8 & $\begin{array}{l}\text { Investigate the effects } \\
\text { on glucose/lipid } \\
\text { metabolism in first- } \\
\text { episode schizophrenia }\end{array}$ & $\begin{array}{l}\text { Statistically significant increases in BMI and } \\
\text { WHR with clozapine, olanzapine, and sulpiride; } \\
\text { statistically significant increases in insulin, } \\
\text { C-peptide, and IRI levels in all groups (higher } \\
\text { for clozapine and olanzapine); clozapine and } \\
\text { olanzapine associated with greater increases in TG }\end{array}$ \\
\hline $\begin{array}{l}\text { Wu et } \mathrm{al}^{79} \\
(\mathrm{RCT})\end{array}$ & $\begin{array}{l}\text { Olanzapine } \\
\text { Clozapine } \\
\text { Risperidone } \\
\text { Sulpiride }\end{array}$ & $\begin{array}{l}25 / 24 \\
33 / 30 \\
31 / 29 \\
31 / 29\end{array}$ & 8 & $\begin{array}{l}\text { Investigate the sex } \\
\text { difference in effects of } \\
\text { clozapine, olanzapine, } \\
\text { risperidone, sulpiride } \\
\text { on glucose and lipid } \\
\text { metabolism in first- } \\
\text { episode schizophrenia }\end{array}$ & $\begin{array}{l}\text { Significant increase in mean BMI for olanzapine, } \\
\text { clozapine and sulpiride from baseline (olanzapine: } \\
\text { I. } 2 \mathrm{I} \pm 0.76 \text { in males and } 0.76 \pm 0.37 \text { in females, } \\
P=0.178) \text {; significant increase in mean WHR for } \\
\text { males receiving olanzapine }(0.03 \pm 0.03 \text { in males } \\
\text { versus }-0.01 \pm 0.02 \text { for females, } P=0.042 \text { for } \\
\text { difference between groups); significant increase in } \\
\text { insulin, } C \text {-peptide and IRI in all groups }(P<0.05) \text {; } \\
\text { increase in TG levels significantly greater in males } \\
(P=0.002)\end{array}$ \\
\hline
\end{tabular}

(Continued) 
Table 6 (Continued)

\begin{tabular}{|c|c|c|c|c|c|}
\hline $\begin{array}{l}\text { Reference } \\
\text { (design) }\end{array}$ & $\begin{array}{l}\text { Treatment } \\
\text { arms }\end{array}$ & $\begin{array}{l}\text { Number of } \\
\text { patients }^{a}\end{array}$ & $\begin{array}{l}\text { Duration } \\
\text { (weeks) }\end{array}$ & $\begin{array}{l}\text { Primary or specified } \\
\text { safety objective }\end{array}$ & Outcomes \\
\hline $\begin{array}{l}\text { Yang et } \mathrm{al}^{31} \\
\text { (retrospective } \\
\text { review) }\end{array}$ & Nil, claims data & 40,561 & - & $\begin{array}{l}\text { Compare the prevalence of } \\
\text { EPS between FGA and SGA } \\
\text { using anti-parkinsonian agent } \\
\text { prescribing rates }\end{array}$ & $\begin{array}{l}\text { Crude coprescribing rate of anti-parkinsonian } \\
\text { agents: quetiapine }<\text { clozapine }<\text { olanzapine }< \\
\text { thioridazine }<\text { zotepine }<\text { chlorpromazine }< \\
\text { risperidone }<\text { sulpiride }<\text { clotiapine }<\text { flupentixol } \\
<\text { haloperidol }<\text { zuclopenthixol }<\text { trifluoperazine } \\
<\text { loxapine }\end{array}$ \\
\hline $\begin{array}{l}\text { Yang et } \mathrm{al}^{33} \\
\text { (nested case- } \\
\text { control) }\end{array}$ & $\begin{array}{l}\text { Pneumonia } \\
\text { Controls }\end{array}$ & $\begin{array}{l}571 \\
2,227\end{array}$ & - & $\begin{array}{l}\text { Explore the association } \\
\text { between antipsychotics/ } \\
\text { mood stabilizers and the } \\
\text { risk of pneumonia }\end{array}$ & $\begin{array}{l}\text { Dose-dependent increase in risk of pneumonia: } \\
\text { olanzapine (adjusted RR 2.97, } P<0.00 \text { I), clozapine } \\
(\text { RR 2.59, } P<0.0 \text { I), haloperidol (RR } 3.68 \text {, } \\
P<0.00 \text { I); lithium associated with decreased risk }\end{array}$ \\
\hline
\end{tabular}

Note: ${ }^{a}$ Enrolled/completed.

Abbreviations: AIMS, Abnormal Involuntary Movement Scale; BMI, body mass index; Cl, confidence interval; EPS, extrapyramidal syndrome; FBG, fasting blood glucose; FGA, first-generation antipsychotics; HDL-C, high-density lipoprotein cholesterol; IRI, insulin resistance index; LDL-C, low-density lipoprotein cholesterol; NR, not reported; OR, odds ratio; RCT, randomized controlled trial; RR, relative risk; SGA, second-generation antipsychotics; TC, total cholesterol; TG, triglyceride; TNF, tumor necrosis factor; WHR, waist-hip ratio.

and extrapyramidal symptoms were the most commonly investigated end points (Table 6). ${ }^{30,31,35,37,66,69-79}$ Two studies also investigated the risk of pneumonia associated with second-generation antipsychotics, including olanzapine (Table 6). ${ }^{28,33}$

\section{Weight gain}

Olanzapine was associated with variable amounts of weight gain as measured by actual weight, waist-to-hip ratio, or body mass index..$^{24,30,35,66,73-75}$ Total mean weight gain tended to be greater in studies with longer periods of follow-up compared with studies of shorter duration. ${ }^{24,66,70,74}$ However, the average rate of weight gain over the whole study period was greater in the studies of shorter duration, suggesting that the greatest weight gain may occur in the initial stages of olanzapine therapy ${ }^{66,70,74}$ In comparative studies, olanzapine was generally associated with greater levels of weight gain than other antipsychotics. . $^{21,36,38,41,43,56,60,61,64,66,67,73-75,77,80}$

Multiple factors were associated with weight gain in patients receiving olanzapine in a 6-month observational study. ${ }^{30}$ These factors included region, housing conditions, stronger appetite, excessive amount of food needed to feel full, eating until uncomfortably full, thoughts preoccupied with food, meal location, increased meal frequency, evening snacks, and a lower amount of vigorous exercise. ${ }^{30}$ Additional factors associated with treatment-emergent weight gain identified from a post hoc analysis of observational data included consumption of red meat, comfortably full sensation when finished eating, social activity level, and sex. ${ }^{69}$ These factors were considered useful for early identification of candidates for weight control intervention during olanzapine therapy ${ }^{69}$
In one RCT, weight gain was greater in men than in women, although this difference was not statistically significant (body mass index change $1.21 \pm 0.76 \mathrm{~kg}$ for men versus $0.76 \pm 0.37 \mathrm{~kg}$ for women, $P=0.178) .{ }^{79}$ Another study observed a positive association between olanzapine monotherapy and low levels of ghrelin. ${ }^{72}$

\section{Metabolic changes}

Throughout the safety studies, the most commonly assessed metabolic parameters were levels of glucose, insulin, insulin resistance, and lipids. Among these parameters, the greatest change during treatment with olanzapine was in triglyceride levels, with the results of six studies finding a $20.2 \%-50.7 \%$ relative increase in triglyceride levels in patients receiving olanzapine. ${ }^{35,37,73,75,78,79}$ A statistically significant increase in fasting blood glucose $(0.29-1.1 \mathrm{mmol} / \mathrm{L}$ over 12 weeks) during treatment with olanzapine therapy was noted in two studies. ${ }^{35,73}$ Significant increases in insulin levels and the insulin resistance index during treatment with olanzapine were observed in three studies. ${ }^{73,75,79}$ In these studies, mean baseline insulin levels increased by approximately $60 \%-100 \%$ at end point after treatment with olanzapine. ${ }^{73,75,79}$ In addition, small increases in high-density lipoprotein cholesterol and moderate increases in total cholesterol and low-density lipoprotein cholesterol $(3.4 \%-8.3 \%, 7.5 \%-23.6 \%$, and $10.7 \%-28.3 \%$ relative increase versus baseline levels, respectively) were reported. $35,37,73,75,78$ Unfavorable changes in these metabolic parameters were also observed during treatment with other atypical antipsychotics. However, the extent of these changes was often greater in some patients treated with olanzapine therapy. Despite this, the incidence of metabolic syndrome in patients treated with olanzapine 
was found to be similar to that with risperidone in one comparative study. ${ }^{74}$

\section{Extrapyramidal symptoms}

A relatively low rate of extrapyramidal symptoms was reported in patients receiving olanzapine compared with other antipsychotics. ${ }^{24}$ This was supported by a retrospective review of data claims that found anti-parkinsonian drug use among patients treated with olanzapine was lower than that used in patients receiving a wide range of antipsychotics, except quetiapine and clozapine. ${ }^{31}$

\section{Other adverse events}

In one cohort study and one case-control study, current use of second-generation antipsychotics was associated with an increased risk of pneumonia. ${ }^{28,33}$ For olanzapine, the adjusted risk ratio reported in these studies was $1.83(95 \%$ confidence interval 1.48-2.28) and 2.97 (95\% confidence interval 1.90-4.66). ${ }^{28,33}$ In patients with bipolar disorder, this elevated risk was higher in those receiving combination therapy (eg, olanzapine + valproic acid).$^{33}$ In both studies, the crude incidence of pneumonia overall was low (1.09-1.12 cases per 100 person years).

\section{Discussion}

To our knowledge, this is the first systematic review of antipsychotic use conducted exclusively in Chinese patients with schizophrenia or bipolar disorder. Although key pharmacokinetic parameters of olanzapine have been shown to be similar in Chinese and Caucasian patients, ${ }^{81}$ synthesized data have not been previously available to allow clinical outcomes to be compared. The overall findings of this systematic review suggest that the efficacy, effectiveness, and safety of olanzapine in Chinese populations are consistent with those observed in non-Chinese populations. Importantly, improvements in a variety of symptom scores from baseline were observed in Chinese patients with schizophrenia or bipolar disorder treated with olanzapine. Further, no new safety signals were reported for olanzapine in Chinese populations. Overall, there were more publications that assessed the use of olanzapine for the treatment of schizophrenia than for bipolar disorder, which may reflect the relative prevalence of these conditions in the People's Republic of China, ${ }^{2}$ and possibly a lower awareness of bipolar disorder in the Chinese population. However, actual study numbers still suggest a need for more research related to the use of antipsychotics for bipolar disorder in the Chinese context.
The efficacy of olanzapine in Chinese patients with schizophrenia observed in studies included in this review was consistent with that observed in many large-scale international studies. For example, the results of several major studies in non-Chinese populations report relative PANSS reductions from baseline of $19.0 \%-49.9 \% .{ }^{82-87}$ These values are within the range found in studies in Chinese populations. Similarly, response rates in these international studies (44.9\%-78.0\%) are also similar to the values observed in Chinese populations. ${ }^{82-86}$ Taken at face value, efficacy figures for olanzapine reported in many Chinese studies in this review appear greater than those reported in many largescale international studies. The phenomenon of studies from the People's Republic of China favorably overestimating the effect of treatment has been noted elsewhere. ${ }^{88}$ However, limitations in the reporting of the Chinese studies, and the heterogeneity of methods and outcomes makes it difficult to investigate the differences between the Chinese and nonChinese populations observed in this review. Treatment studies that either directly compare efficacy in Chinese and non-Chinese populations or allow such comparisons would be useful to address this issue. Finally, it should be stressed that the heterogeneity of definitions for response throughout these studies means that interpretation of these results is difficult. Harmonization and consensus between investigators in terms of study features such as definitions for response would help in this regard.

One notable difference between Chinese and non-Chinese populations relates to the relative efficacy of olanzapine versus other antipsychotics. Studies of Chinese populations in this review generally found no significant difference in efficacy between olanzapine and comparator agents. In contrast, comparative studies in non-Chinese populations have indicated that improvements in efficacy measures often favor patients receiving olanzapine. This finding has been confirmed by a meta-analysis of 50 studies which found that olanzapine improved the PANSS total score to a greater extent than aripiprazole, quetiapine, risperidone, or ziprasidone, but not amisulpride or clozapine. ${ }^{89}$ Further, fewer patients treated with olanzapine discontinued treatment due to lack of efficacy compared with those treated with quetiapine, risperidone, or ziprasidone. These results are confirmed by a more recent large meta-analysis of 212 suitable trials with data for 43,049 participants, which also found olanzapine to be more effective in terms of overall change in symptoms (standardized mean difference) than other included antipsychotics, except for amisulpride and clozapine. ${ }^{5}$ Similar to the previous meta-analysis, olanzapine 
also scored higher in terms of all-cause discontinuation than all other antipsychotics, except amisulpride and clozapine. ${ }^{5}$ The possible reasons for the discrepancy between Chinese and non-Chinese populations are many and might include, for example, genetic variation, which is an important contributor to racial and ethnic differences in response to pharmaceutical agents. However, no studies included in this review provided data to allow such factors to be explored. One possible alternative explanation provided by the studies relates to the small sample size and the short duration of many of the Chinese comparative studies. In terms of sample size, Chinese studies in this review typically enrolled fewer than 50 patients per treatment arm, so may be underpowered to show statistically significant differences. Interestingly, a larger Chinese study in this review (260 enrolled patients) found a statistically significant difference in PANSS favoring olanzapine over ziprasidone at end point, a finding consistent with similar studies in the international literature. ${ }^{90}$ The short duration ( $<12$ weeks) of many of the Chinese trials limited these to an assessment of the acute treatment response only. However, a lack of difference in efficacy between olanzapine and other antipsychotics has also been shown in international comparative studies of short duration, where significant differences became apparent with longer follow-up. ${ }^{91-94}$

These findings highlight the potential limitations of shortterm randomized trials for detecting meaningful treatment differences, which have been shown to be better assessed in studies offering long-term follow-up, particularly in a realworld setting. For example, 3-year results from the SOHO (Schizophrenia Outpatient Health Outcomes) observational study revealed clear differences between olanzapine and other antipsychotics at end point, while also showing that results from randomized trials such as the CATIE (Clinical Antipsychotic Trials of Intervention Effectiveness) study may have underestimated true treatment effects. ${ }^{95,96}$ This may be related to design aspects, particularly blinding, which may lead to decreased confidence in the medication received and a greater likelihood of medication change. ${ }^{95}$ Further, the opportunity to freely change medication within the protocol may have prompted discontinuation of the first medication at a greater rate than seen in routine clinical practice. ${ }^{95}$

Studies in both Chinese and non-Chinese populations have shown that olanzapine is efficacious in patients with bipolar manic or mixed episodes. In Chinese populations, two 4-week RCTs found that olanzapine treatment was associated with reductions in YMRS scores of approximately 25 points. ${ }^{46,48}$ In non-Chinese populations, a 4-week RCT and 6-month openlabel continuation trial reported YMRS score reductions from baseline to end point of 14.8 and 18.0 points, respectively. ${ }^{97,98}$ However, as noted, differences in study characteristics make it impossible to directly compare results between these studies from different populations. The remission rate (defined as YMRS $\leq 12$ ) for olanzapine in one Chinese study was $82.1 \%$, which is supported by the rate $(88.3 \%)$ reported in an open-label trial in non-Chinese patients. ${ }^{97}$ Similar to the findings for schizophrenia, the response rates associated with olanzapine treatment in Chinese patients with bipolar disorder were typically higher than those observed in nonChinese populations. ${ }^{46,48,97,98}$ Once again, studies designed to address this issue are needed to confirm if true differences exist between Chinese and non-Chinese populations.

Real-world effectiveness, especially the prevention of discontinuation and the improvement in functional capacity and quality of life, is a critical parameter by which antipsychotic therapy should be assessed. Compared with the large number of studies assessing efficacy, this review of olanzapine in Chinese populations found a lack of large, well designed, effectiveness studies. There is good evidence that treatment discontinuation is associated with relapse and need for hospitalization and predicts a worse long-term outcome. ${ }^{99}$ Recent research confirms that psychiatric-related hospitalizations in the People's Republic of China use more medical resources and contribute to higher direct medical costs than community-based care. ${ }^{100}$ Inpatient costs are primarily related to nondrug medical care, suggesting that use of more effective treatments to minimize the risk of hospitalization could reduce total health expenditure. ${ }^{101}$ Research in Chinese populations also suggests that combining psychosocial interventions with effective medical treatment for patients with early schizophrenia lowers the risk of treatment discontinuation and relapse as well as improving insight, quality of life, and social functioning. Overall, these findings should motivate practitioners to implement effective treatment strategies early in the course of a psychotic illness. Among Chinese patients with schizophrenia, total long-term discontinuation rates with olanzapine (around $40 \%$ at 12 months) were similar to those noted in the large observational SOHO trial in non-Chinese populations $(36 \%$ at 3 years). ${ }^{95}$ Discontinuation rates for olanzapine in Chinese populations were not statistically significantly different from other second-generation antipsychotics. ${ }^{22,24}$ In contrast, a meta-analysis of non-Chinese populations found olanzapine to have the second lowest rate of discontinuation among 15 antipsychotics. ${ }^{5}$ Further research related to discontinuation, especially among patients with bipolar disease, appears warranted in the People's Republic of China. 
Regarding quality of life, a recent post hoc analysis of a study conducted in Chinese patients with schizophrenia who switched from typical antipsychotics to olanzapine suggests that symptomatic improvement is strongly correlated with improvements in self-rated quality of life across multiple domains. ${ }^{102}$ Studies in both Chinese and nonChinese populations confirm that treatment with olanzapine is associated with quality of life improvements in different measures. ${ }^{25,27,103-105}$ An open-label study in non-Chinese patients with schizophrenia supports the specific improvements in the role physical and role emotional domains noted in Chinese populations in this systematic literature review. ${ }^{105}$ Finally, improvements in various aspects of cognitive function in Chinese populations with early and first-episode schizophrenia treated with olanzapine were observed in this review. ${ }^{19,23}$ However, the effects of atypical antipsychotics on neurocognition reported in international studies have shown mixed results. Olanzapine has been associated with neurocognitive improvements in short-term studies and patients with early psychosis. ${ }^{106,107}$ However, in other long-term studies, neurocognitive improvements have not been observed. ${ }^{108}$ It should also be noted that studies of cognition are limited by the possible effects of learning and small effect sizes.

Weight gain and metabolic changes were identified as the most commonly reported adverse events with the use of olanzapine in Chinese populations. Regarding weight gain, the present review shows that the levels of mean weight gain in short-term and long-term studies of Chinese patients receiving olanzapine were generally consistent with those seen in non-Chinese patients. For example, a meta-analysis of short-term studies of non-Chinese populations with schizophrenia or bipolar disorder observed mean weight gain levels of approximately $4 \mathrm{~kg}$ with olanzapine treatment. ${ }^{109} \mathrm{In}$ long-term studies lasting 6 to 24 months, mean weight gain levels of $1.5-11.5 \mathrm{~kg}$ were associated with olanzapine treatment. ${ }^{110}$ Weight gain in Chinese populations was generally greater during treatment with olanzapine than with comparator second-generation antipsychotics. This finding has also been noted in numerous comparative studies in the international literature and confirmed by a large-scale meta-analysis. ${ }^{5}$ In Chinese patients, weight gain tended to increase more rapidly in the short-term (eg, 6-12 weeks), a finding that has also been observed in long-term clinical studies in nonChinese populations. ${ }^{111}$ Hence, attention to early weight gain ( $\geq 2 \mathrm{~kg}$ in the first 3 weeks of therapy) has a practical clinical aspect in that this tends to predict more substantial weight gain. ${ }^{12}$ Studies included in this review also identified multiple environmental, eating, and lifestyle factors that should be considered when assessing weight gain in Chinese patients that occurs during olanzapine therapy. ${ }^{30,69}$ These factors can also assist clinicians in the early identification of patients who may be appropriate candidates for weight management programs ${ }^{69}$ Such programs may lower the risk of clinically significant weight gain during treatment with olanzapine and also provide additional clinical and functional benefits, including better treatment response and reduced impairment in work activities. ${ }^{4}$ Regarding the changes in metabolic parameters, the results observed in Chinese populations have been noted in numerous studies in non-Chinese populations. ${ }^{110,113}$ Increases in blood glucose and insulin have been noted in studies among both Chinese and non-Chinese populations. However, the duration of most of these studies is considerably shorter than the time frame over which metabolic complications such as diabetes develop. ${ }^{110,113}$

The main strength of this systematic review was the inclusion of studies from a broad search of the literature. Inclusion of studies published in Chinese language journals greatly expanded the evidence available to assess the clinical outcomes of treatment with olanzapine and helped overcome the inherent language bias that is present in systematic reviews that only include articles published in English. However, assessment of the quality of many of the studies conducted in Chinese populations was hampered by the poor reporting of several methodological aspects, including randomization procedures, blinding, and inadequate reporting of baseline demographics. These factors, in particular, as well as the possible presence of confounding variables that were not apparently controlled for as part of the study design represent serious potential sources of bias. As a result, the combined results of this review of Chinese population studies need to be interpreted with caution. The use of studies published in Chinese medical journals has been the subject of debate. While critical publication processes such as peer review and article indexing in Chinese journals continue to improve, many study-specific issues such as adequate detail regarding methods and proper use of statistical tests remain. ${ }^{17}$ Initiatives such as CONSORT (Consolidated Standards of Reporting Trials) encourage standardized reporting of clinical trials to improve transparency and avoid the problems that can arise from inadequate reporting. ${ }^{114}$ Despite this, few Chinese medical journals recommend CONSORT, and RCTs published in Chinese journals generally fall short of these standards. ${ }^{115}$

The secondary aim of this systematic literature review was to identify opportunities for further research in the People's Republic of China to improve the care of patients with schizophrenia or bipolar disorder. Even within 
the defined scope of this review, it seems clear that the abundance of relatively small and short-term efficacy studies have merely confirmed the overall findings of multiple studies conducted in other countries. Good quality effectiveness studies that incorporate outcomes (eg, discontinuation rate) relevant to patients, carers, clinicians, and wider society are lacking. Ideally, these studies should take place in naturalistic settings using long-term time horizons and might also address sociocultural aspects identified in Chinese settings (eg, effects of treatment on carers or hostile/ antisocial behavior).

Finally, in spite of the challenges of interpreting and applying the results of Chinese language studies, we believe the incorporation of research from the People's Republic of China into reviews of the literature should continue. A recent review of Asian guidelines for depression noted that most recommendations are based on consensus derived from Western research data. ${ }^{116}$ The discrepancy between the context in which these recommendations are developed and local practices and circumstances may underlie their failure to be implemented. Instead, treatment guidelines need to evolve from external consensus to incorporate local evidence that considers issues such as cost effectiveness. In this regard, local evidence-based information is the ingredient most greatly needed but in shortest supply. Efforts to increase both the quantity and quality of evidence from the People's Republic of China are therefore encouraged.

\section{Conclusion}

This systematic literature review of the safety and efficacy of olanzapine treatment in Chinese populations suggests that the overall efficacy, effectiveness, and safety/tolerability of olanzapine are consistent with that observed in non-Chinese populations. Although inclusion of Chinese language studies provided a larger body of evidence and helped overcome language bias, many of the studies were limited in terms of the quality of reporting. There has been an increasing recognition of chronic mental disorders in the People's Republic of China and a commitment of the Chinese government to improve treatment through health reform and increased spending. In this setting, there is an ongoing need for an evidence-based approach to psychotropic therapy in the People's Republic of China with an increasing focus on well-designed effectiveness studies relevant to the Chinese context. Inclusion of Chinese language studies in systematic reviews may also further encourage efforts to improve the quality of Chinese studies and the exchange of scientific and clinical knowledge with other countries.

\section{Author contributions}

All authors, including Eli Lilly employees, were involved in the development of the concept and literature search strategy for this review, collection of publications, synthesis of published data, and preparation of the manuscript.

\section{Disclosure}

This systematic review was sponsored by Eli Lilly, manufacturer/licensee of Zyprexa (olanzapine). Medical writing assistance was provided by Mark Snape and Serina Stretton of ProScribe Medical Communications and was funded by Eli Lilly. ProScribe's services complied with international guidelines for Good Publication Practice. HBX, LL, WM, and TT are Eli Lilly employees. In addition, TT is an Eli Lilly and company shareholder. HZ is contracted by Eli Lilly as an intern from the China Pharmaceutical University. The authors report no other conflicts of interest in this work.

\section{References}

1. Hvistendahl M. China. World's biggest health care system goes under the knife. Science. 2013;339(6119):505-507.

2. Phillips MR, Zhang J, Shi Q, et al. Prevalence, treatment, and associated disability of mental disorders in four provinces in China during 2001-2005: an epidemiological survey. Lancet. 2009;373(9680): 2041-2053.

3. Robinson D, Woerner MG, Alvir JM, et al. Predictors of relapse following response from a first episode of schizophrenia or schizoaffective disorder. Arch Gen Psychiatry. 1999;56(3):241-247.

4. Montgomery W, Liu L, Stensland MD, Xue HB, Treuer T, AscherSvanum H. The personal, societal, and economic burden of schizophrenia in the People's Republic of China: implications for antipsychotic therapy. Clinicoecon Outcomes Res. 2013;5:407-418.

5. Leucht S, Cipriani A, Spineli L, et al. Comparative efficacy and tolerability of 15 antipsychotic drugs in schizophrenia: a multiple-treatments meta-analysis. Lancet. 2013;382(9896):951-962.

6. Phillips MR. Characteristics, experience, and treatment of schizophrenia in China. Dialogues Clin Neurosci. 2001;3(2):109-119.

7. Ito H, Okumura Y, Higuchi T, Tan CH, Shinfuku N. International variation in antipsychotic prescribing for schizophrenia: pooled results from the research on East Asia psychotropic prescription (REAP) studies. Open J Psychiatr. 2012;2:340-346.

8. Xiang YT, Weng YZ, Leung CM, Tang WK, Ungvari GS. Clinical and social determinants of antipsychotic polypharmacy for Chinese patients with schizophrenia. Pharmacopsychiatry. 2007;40(2):47-52.

9. Aggarwal NK, Tao H, Xu K, Stefanovics E, Zhening L, Rosenheck RA. Comparing the PANSS in Chinese and American inpatients: cross-cultural psychiatric analyses of instrument translation and implementation. Schizophr Res. 2011;132(2-3):146-152.

10. Lilly Suzhou Pharmaceutical Co. Ltd. Zyprexa Approved Product Information (Chinese version). Data on file. Accessed October 17, 2013. English translation.

11. Pang N, Wang T. Analysis for the antipsychotics usage during 2008 to 2009. J Mod Med Health. 2012;28(9):1381-1382.

12. Yang P. [The usage of antipsychotics]. Chinese and Foreign Medical Research. 2013;11(18):59-60. Chinese.

13. Xiang YT, Kreyenbuhl J, Dickerson FB, et al. Use of first- and secondgeneration antipsychotic medications in older patients with schizophrenia in Asia (2001-2009). Aust N Z J Psychiatry. 2012;46(12): $1159-1164$. 
14. Buckley PF. Olanzapine: a critical review of recent literature. Expert Opin Pharmacother. 2005;6(12):2077-2089.

15. Bhana N, Perry CM. Olanzapine: a review of its use in the treatment of bipolar I disorder. CNS Drugs. 2001;15(11):871-904.

16. Fulton B, Goa KL. Olanzapine. A review of its pharmacological properties and therapeutic efficacy in the management of schizophrenia and related psychoses. Drugs. 1997;53(2):281-298.

17. Fung IC. Chinese journals: a guide for epidemiologists. Emerg Themes Epidemiol. 2008;5:20.

18. Wang MY, Zhou ZX, Fang HL, Liu XL. The bibliometric characteristics of Chinese medical core journals. Serials Review. 2011;37(1):9-13.

19. Wang CH, Li Y, Yang J, et al. A randomized controlled trial of olanzapine improving memory deficits in Han Chinese patients with firstepisode schizophrenia. Schizophr Res. 2013;144(1-3):129-135.

20. Zhu QY, Pi JF. [The effect of olanzapine on the quality of life of patients with schizophrenia]. Herald of Medicine. 2012;31(3):334-336. Chinese.

21. Xie Q, Feng SH, Zeng HL. [Efficacies of paliperidone extended-release tablets and olanzapine for treating schizophrenia in children and adolescents]. Chinese Journal of New Drugs. 2012;21(16):1916-1919. Chinese.

22. Fang MS, Zhao JP, Guo XF. [Maintenance treatment effectiveness of seven antipsychotic drugs in schizophrenic patients: a 1-year follow-up study]. Chinese Journal of Psychiatry. 2009;42(1):1-6. Chinese.

23. Guo X, Zhai J, Wei Q, et al. Neurocognitive effects of first- and secondgeneration antipsychotic drugs in early-stage schizophrenia: a naturalistic 12-month follow-up study. Neurosci Lett. 2011;503(2):141-146.

24. Guo X, Fang M, Zhai J, et al. Effectiveness of maintenance treatments with atypical and typical antipsychotics in stable schizophrenia with early stage: 1-year naturalistic study. Psychopharmacology (Berl). 2011;216(4):475-484.

25. Guo X, Zhang Z, Zhai J, et al. Effects of antipsychotic medications on quality of life and psychosocial functioning in patients with early-stage schizophrenia: 1-year follow-up naturalistic study. Compr Psychiatry. 2012;53(7):1006-1012.

26. Yen CF, Cheng CP, Huang CF, Yen JY, Ko CH, Chen CS. Quality of life and its association with insight, adverse effects of medication and use of atypical antipsychotics in patients with bipolar disorder and schizophrenia in remission. Bipolar Disord. 2008;10(5):617-624.

27. Fang M, Li L, Zhao J, et al. [Effect of antipsychotic drugs on life quality of schizophrenic patients: one year follow-up study]. Zhong Nan Da Xue Xue Bao Yi Xue Ban. 2009;34(9):850-855. Chinese.

28. Kuo CJ, Yang SY, Liao YT, et al. Second-generation antipsychotic medications and risk of pneumonia in schizophrenia. Schizophr Bull. 2013;39(3):648-657.

29. Lu Z, Hu J, Chen CK, et al. Effectiveness and safety of olanzapine in the treatment of schizophrenia among Asian patients switching from conventional antipsychotics. Prog Neuropsychopharmacol Biol Psychiatry. 2007;31(1):32-40.

30. Treuer T, Hoffmann VP, Chen AK, et al. Factors associated with weight gain during olanzapine treatment in patients with schizophrenia or bipolar disorder: results from a six-month prospective, multinational, observational study. World J Biol Psychiatry. 2009;10(4 Pt 3):729-740.

31. Yang SY, Kao Yang YH, Chong MY, Yang YH, Chang WH, Lai CS. Risk of extrapyramidal syndrome in schizophrenic patients treated with antipsychotics: a population-based study. Clin Pharmacol Ther. 2007;81(4):586-594.

32. Jian WY, Miao GD. [The efficacy and safety of atypical antipsychotic drugs combined with sodium valproate in the treatment of bipolar mania]. Guangdong Medical Journal. 2013;34(4):641-616. Chinese.

33. Yang SY, Liao YT, Liu HC, Chen WJ, Chen CC, Kuo CJ. Antipsychotic drugs, mood stabilizers, and risk of pneumonia in bipolar disorder: a nationwide case-control study. J Clin Psychiatry. 2013;74(1): e79-e86.

34. Kay SR, Fiszbein A, Opler LA. The positive and negative syndrome scale (PANSS) for schizophrenia. Schizophr Bull. 1987;13(2):261-276.
35. Chen JX, Wu SY, Lin R. [The efficacy and impacts on glucose and lipid metabolism of ziprasidone and olanzapine in the treatment of elder patients with schizophrenia]. Guangdong Medical Journal. 2012;33(7):1006-1008. Chinese.

36. Chen Q, Liu XL, Chen YZ. [Research on efficacy and safety of olanzapine and ziprasidone in the treatment of schizophrenia]. Chinese Journal of Hospital Pharmacy. 2008;28(21):1856-1858. Chinese.

37. Chen XH. [The efficacy of domestic and imported olanzapine in the treatment of schizophrenia and the impacts on glucose and lipid metabolism]. Guangdong Medical Journal. 2010;31(13):1736-1738. Chinese.

38. Li YM, Zhao JP, Ou JJ, Wu RR. Efficacy and tolerability of ziprasidone vs olanzapine in naive first-episode schizophrenia: a 6-week, randomized, open-label, flexible-dose study. Pharmacopsychiatry. 2012;45(5):177-181.

39. Tan H, Wang JM. [Controlled clinical trial of domestic olanzapine in the treatment of schizophrenia]. Chongqing Medical Journal. 2009;38(7):787-788. Chinese.

40. Wang XF, Cui GM, Ma J. [The efficacy observation of aripiprazole in the treatment of 48 patients with first-episode schizophrenia]. Shandong Medical Journal. 2010;50(31):57-58. Chinese.

41. Yang LH, Wei KL, Su SY. [Clinical efficacy and safety of olanzapine and risperidone in the treatment of first episode schizophrenia]. Chinese Journal of Clinical Pharmacology. 2010;26(9):647-649. Chinese.

42. Yu LL, Wang XY, Jin GX. [The effects of anti-schizophrenia on serum level of estrogen in male patients with schizophrenia]. Chinese Journal of Nervous and Mental Diseases. 2012;38(12):742-746. Chinese.

43. Zhu QY, Pi JF. [A comparative study of paliperidone and olanzapine in the treatment of treatment-refractory schizophrenia]. Chinese Journal of New Drugs. 2012;21(6):666-669. Chinese.

44. Li HJ, Wu AG, Zhao HY. [The correlation analysis between the efficacy of olanzapine in the treatment of schizophrenia and the blood concentration]. Chinese Journal of Nervous and Mental Diseases. 2003;29(5):363-365. Chinese.

45. Liu YP, Liu EY, Lan XE. [Controlled study of quetiapine and olanzapine combined with sodium valproate in the treatment of female patients with acute manic episode]. J Pract Med. 2009;25(1):123-125. Chinese.

46. Niufan G, Tohen M, Qiuqing A, et al. Olanzapine versus lithium in the acute treatment of bipolar mania: a double-blind, randomized, controlled trial. J Affect Disord. 2008;105(1-3):101-108.

47. Tohen M, Calabrese JR, Sachs GS, et al. Randomized, placebocontrolled trial of olanzapine as maintenance therapy in patients with bipolar I disorder responding to acute treatment with olanzapine. Am J Psychiatry. 2006;163(2):247-256.

48. Yang PD, Li J, Chen DC. [A random and controlled trial for evaluating the efficacy and safety of olanzapine and lithium in the treatment of bipolar or mixed type mania]. Chinese Journal of New Drugs. 2008; 17(1):67-70. Chinese.

49. Bech P, Rafaelsen OJ, Kramp P, Bolwig TG. The Mania Rating Scale: scale construction and inter-observer agreement. Neuropharmacology. 1978;17(6):430-431.

50. Overall JE, Gorham DR. The Brief Psychiatric Rating Scale. Psychol Rep. 1962;10:799-812.

51. Montgomery SA, Asberg M. A new depression scale designed to be sensitive to change. Br J Psychiatry. 1979;134:382-389.

52. Young RC, Biggs JT, Ziegler VE, Meyer DA. A rating scale for mania: reliability, validity and sensitivity. Br J Psychiatry. 1978;133:429-435.

53. Tohen M, McDonnell DP, Case M, et al. Randomised, double-blind, placebo-controlled study of olanzapine in patients with bipolar I depression. Br J Psychiatry. 2012;201(5):376-382.

54. Shen T, Li WJ. [The efficacy analysis of small-dose olanzpine in treatment of 12 patients with schizophrenia]. Shanghai Archives of Psychiatry. 2000;12(1):48-49. Chinese.

55. Shu L, Liu P, Zhou M. [Olanzapine in the treatment of schizophrenia: an open trial clinical study]. Chinese Journal of Psychiatry. 1999;32(4):223-225. Chinese. 
56. Wang Y, Cai LW, Zhang HX. [The efficacy and adverse effects of haloperidol and olanzapine: a randomized controlled study]. Chinese Journal of Nervous and Mental Diseases. 2012;38(4):217-221. Chinese.

57. Yang XN, Mei QY. [A comparison of olanzapine and risperidone in the treatment of first-episode schizophrenia]. Shanghai Archives of Psychiatry. 2003;15(6):338-340. Chinese.

58. Zheng HB, Deng HH, Zhou L. [Open-label trial of olanzapine in the maintenance treatment of 23 patients with schizophrenia]. Shanghai Archives of Psychiatry. 2000;12(1):43-44. Chinese.

59. Chang FW, Wang CH, Zhao Z. [A comparison of clinical efficacy between olanzapine and chlorpromazine in the treatment of positive symptoms of schizophrenia]. Chinese Journal of New Drugs and Clinical Remedies. 2003;22(6):357-359. Chinese.

60. Chen JJ, Chan HY, Chen CH, Gau SS, Hwu HG. Risperidone and olanzapine versus another first generation antipsychotic in patients with schizophrenia inadequately responsive to first generation antipsychotics. Pharmacopsychiatry. 2012;45(2):64-71.

61. Du NQ. [The analysis for comparison of efficacy and safety of ziprasidone and olanzapine in treatment of early schizophrenia]. Chongqing Medical Journal. 2012;41(28):2938-2939. Chinese.

62. Gao GL, Chen L. [The effectiveness of olanzapine in the treatment of first episode schizophrenia]. Shanghai Archives of Psychiatry. 2003;15(1):33-34. Chinese.

63. Guo JH, Weng YZ, Fang Z. [Open-label trial of olanzapine in the treatment of 33 patients with schizophrenia]. Shanghai Archives of Psychiatry. 2000;12(1):46-48. Chinese.

64. Ma Q, Li LX, Lian HT. [A controlled comparison study on paliperidone extended-release tablets and olanzapine in the treatment of schizophrenia]. Chinese Journal of New Drugs. 2012;21(22):2658-2661. Chinese.

65. Zhang HY, Li HF, Gang W. [The efficacy and safety of flexible dose of paliperidone extended-release tablets in the treatment of acute schizophrenia: a randomized, double blind olanzapine-controlled study] Chinese Journal of Psychiatry. 2009;42(3):153-157. Chinese.

66. Lee E, Leung CM, Wong E. Atypical antipsychotics and weight gain in Chinese patients: a comparison of olanzapine and risperidone. J Clin Psychiatry. 2004;65(6):864-866.

67. Liang Y. [A clinical comparative study on paliperidone ER in treating acute phase schizophrenia patients]. Chinese Journal of New Drugs. 2011;20(24):2442-2445. Chinese.

68. Cao GX, Xie GJ. [Observation of efficacy and safety of paliperidone sustained release tablets and domestic olanzapine in treatment of schizophrenia]. Chongqing Medical Journal. 2011;40(17):1695-1696. Chinese.

69. Ang Q, Tang J, Zhao JP, et al. [Factors associated with weight gain during six-month olanzapine therapy]. Chinese Journal of Psychiatry. 2011;44(3):1-6. Chinese.

70. Chan HY, Chang CJ, Chiang SC, et al. A randomised controlled study of risperidone and olanzapine for schizophrenic patients with neuroleptic-induced acute dystonia or parkinsonism. J Psychopharmacol. 2010;24(1):91-98.

71. Chan HY, Chiang SC, Chang CJ, et al. A randomized controlled trial of risperidone and olanzapine for schizophrenic patients with neuroleptic-induced tardive dyskinesia. J Clin Psychiatry. 2010;71(9): 1226-1233.

72. Chen VC, Wang TN, Lu ML, et al. Weight gain and ghrelin level after olanzapine monotherapy. Prog Neuropsychopharmacol Biol Psychiatry. 2011;35(2):632-635.

73. Hu S, Yao M, Peterson BS, et al. A randomized, 12-week study of the effects of extended-release paliperidone (paliperidone ER) and olanzapine on metabolic profile, weight, insulin resistance, and betacell function in schizophrenic patients. Psychopharmacol (Berl). 2013:230(1):3-13.

74. Lee E, Leung CM. Atypical antipsychotics and metabolic outcomes in Chinese patients: a comparison of olanzapine and risperidone. $J$ Clin Psychopharmacol. 2008;28(6):707-709.
75. Ou JJ, Xu Y, Chen HH, et al. Comparison of metabolic effects of ziprasidone versus olanzapine treatment in patients with first-episode schizophrenia. Psychopharmacol (Berl). 2013;225(3):627-635.

76. Pratt N, Andersen M, Bergman U, et al. Multi-country rapid adverse drug event assessment: the Asian Pharmacoepidemiology Network (AsPEN) antipsychotic and acute hyperglycaemia study. Pharmacoepidemiol Drug Saf. 2013;22(9):915-924.

77. Su KP, Wu PL, Pariante CM. A crossover study on lipid and weight changes associated with olanzapine and risperidone. Psychopharmacol (Berl). 2005;183(3):383-386.

78. Wu RR, Zhao JP, Liu ZN, et al. Effects of typical and atypical antipsychotics on glucose-insulin homeostasis and lipid metabolism in first-episode schizophrenia. Psychopharmacol (Berl). 2006;186(4): 572-578.

79. Wu RR, Zhao JP, Zhai JG, Guo XF, Guo WB. Sex difference in effects of typical and atypical antipsychotics on glucose-insulin homeostasis and lipid metabolism in first-episode schizophrenia. J Clin Psychopharmacol. 2007;27(4):374-379.

80. Dong HX, Mei HB. [The comparison of quetiapine with olanzapine in the treatment of aged patients with schizophrenia]. Herald of Medicine. 2012;31(2):184-185. Chinese.

81. Sathirakul K, Chan C, Teng L, Bergstrom RF, Yeo KP, Wise SD. Olanzapine pharmacokinetics are similar in Chinese and Caucasian subjects. Br J Clin Pharmacol. 2003;56(2):184-187.

82. Dossenbach MR, Folnegovic-Smalc V, Hotujac L, et al. Double-blind, randomized comparison of olanzapine versus fluphenazine in the longterm treatment of schizophrenia. Prog Neuropsychopharmacol Biol Psychiatry. 2004;28(2):311-318.

83. Fleischhacker WW, McQuade RD, Marcus RN, Archibald D, Swanink R, Carson WH. A double-blind, randomized comparative study of aripiprazole and olanzapine in patients with schizophrenia. Biol Psychiatry. 2009;65(6):510-517.

84. Grootens KP, van Veelen NM, Peuskens J, et al. Ziprasidone vs olanzapine in recent-onset schizophrenia and schizoaffective disorder: results of an 8-week double-blind randomized controlled trial. Schizophr Bull. 2011;37(2):352-361.

85. Lublin H, Haug HJ, Koponen H, Sigmundsson T, Kolb SA. Ziprasidone versus olanzapine, risperidone or quetiapine in patients with chronic schizophrenia: a 12-week open-label, multicentre clinical trial. World J Biol Psychiatry. 2009;10(4 Pt 3):710-718.

86. San L, Arranz B, Perez V, et al. One-year, randomized, open trial comparing olanzapine, quetiapine, risperidone and ziprasidone effectiveness in antipsychotic-naive patients with a first-episode psychosis. Psychiatry Res. 2012;200(2-3):693-701.

87. Tollefson GD, Beasley CM Jr, Tran PV, et al. Olanzapine versus haloperidol in the treatment of schizophrenia and schizoaffective and schizophreniform disorders: results of an international collaborative trial. Am J Psychiatry. 1997;154(4):457-465.

88. Vickers A, Goyal N, Harland R, Rees R. Do certain countries produce only positive results? A systematic review of controlled trials. Control Clin Trials. 1998;19(2):159-166.

89. Komossa K, Rummel-Kluge C, Hunger H, et al. Olanzapine versus other atypical antipsychotics for schizophrenia. Cochrane Database Syst Rev. 2010;3:CD006654.

90. Breier A, Berg PH, Thakore JH, et al. Olanzapine versus ziprasidone: results of a 28-week double-blind study in patients with schizophrenia. Am J Psychiatry. 2005;162(10):1879-1887.

91. Conley RR, Mahmoud R. A randomized double-blind study of risperidone and olanzapine in the treatment of schizophrenia or schizoaffective disorder. Am J Psychiatry. 2001;158(5):765-774.

92. Gureje O, Miles W, Keks N, et al. Olanzapine vs risperidone in the management of schizophrenia: a randomized double-blind trial in Australia and New Zealand. Schizophr Res. 2003;61(2-3): 303-314.

93. Jeste DV, Barak Y, Madhusoodanan S, Grossman F, Gharabawi G. International multisite double-blind trial of the atypical antipsychotics risperidone and olanzapine in 175 elderly patients with chronic schizophrenia. Am J Geriatr Psychiatry. 2003;11(6):638-647. 
94. Keefe RS, Young CA, Rock SL, et al. One-year double-blind study of the neurocognitive efficacy of olanzapine, risperidone, and haloperidol in schizophrenia. Schizophr Res. 2006;81(1):1-15.

95. Haro JM, Suarez D, Novick D, et al. Three-year antipsychotic effectiveness in the outpatient care of schizophrenia: observational versus randomized studies results. Eur Neuropsychopharmacol. 2007;17(4):235-244.

96. Lieberman JA, Stroup TS, McEvoy JP, et al. Effectiveness of antipsychotic drugs in patients with chronic schizophrenia. N Engl J Med. 2005;353(12):1209-1223.

97. Sanger TM, Grundy SL, Gibson PJ, Namjoshi MA, Greaney MG, Tohen MF. Long-term olanzapine therapy in the treatment of bipolar I disorder: an open-label continuation phase study. J Clin Psychiatry. 2001;62(4):273-281.

98. Tohen M, Jacobs TG, Grundy SL, et al. Efficacy of olanzapine in acute bipolar mania: a double-blind, placebo-controlled study. The Olanzipine HGGW Study Group. Arch Gen Psychiatry. 2000;57(9): 841-849.

99. Ascher-Svanum H, Faries DE, Zhu B, Ernst FR, Swartz MS, Swanson JW. Medication adherence and long-term functional outcomes in the treatment of schizophrenia in usual care. $J$ Clin Psychiatry. 2006;67(3):453-460.

100. He X, Wu J, Liu L, Montgomery W, Ye W, Xue HB. Health care resource utilization and direct medical costs among patients with schizophrenia in Tianjin, China. Poster 13 presented at the Fourth World Congress of Asian Psychiatry, August 19-22, 2013, Bangkok, Thailand.

101. Liu L, Ye W, He X, Wu J, Montgomery W, Xue HB. Differential resource use and costs among inpatients and outpatients with schizophrenia in Tianjin, China. Poster 14 presented at the Fourth World Congress of Asian Psychiatry, August 19-22, 2013, Bangkok, Thailand.

102. Montgomery W, Kadziola Z, Ye W, Xue HB, Liu L, Treuer T. Correlation between changes in quality of life and symptomatic improvement in Chinese patients switched from typical antipsychotics to olanzapine. Poster presented at the Fourth World Congress of Asian Psychiatry, August 19-22, 2013, Bangkok, Thailand.

103. Namjoshi MA, Rajamannar G, Jacobs T, et al. Economic, clinical, and quality-of-life outcomes associated with olanzapine treatment in mania. Results from a randomized controlled trial. J Affect Disord. 2002;69(1-3):109-118.

104. Revicki DA, Genduso LA, Hamilton SH, Ganoczy D, Beasley CM Jr. Olanzapine versus haloperidol in the treatment of schizophrenia and other psychotic disorders: quality of life and clinical outcomes of a randomized clinical trial. Qual Life Res. 1999;8(5):417-426.

105. Silva de Lima M, de Jesus Mari J, Breier A, Maria Costa A, Ponde de Sena E, Hotopf M. Quality of life in schizophrenia: a multicenter, randomized, naturalistic, controlled trial comparing olanzapine to first-generation antipsychotics. J Clin Psychiatry. 2005;66(7): 831-838.

106. Bilder RM, Goldman RS, Volavka J, et al. Neurocognitive effects of clozapine, olanzapine, risperidone, and haloperidol in patients with chronic schizophrenia or schizoaffective disorder. Am J Psychiatry. 2002;159(6):1018-1028.
107. Keefe RS, Sweeney JA, Gu H, et al. Effects of olanzapine, quetiapine, and risperidone on neurocognitive function in early psychosis: a randomized, double-blind 52-week comparison. Am J Psychiatry. 2007;164(7):1061-1071.

108. Ayesa-Arriola R, Rodriguez-Sanchez JM, Perez-Iglesias R, et al. Long-term (3-year) neurocognitive effectiveness of antipsychotic medications in first-episode non-affective psychosis: a randomized comparison of haloperidol, olanzapine, and risperidone. Psychopharmacol (Berl). 2013;227(4):615-625.

109. Allison DB, Mentore JL, Heo M, et al. Antipsychotic-induced weight gain: a comprehensive research synthesis. Am J Psychiatry. 1999;156(11):1686-1696.

110. Kantrowitz JT, Citrome L. Olanzapine: review of safety 2008. Expert Opin Drug Saf. 2008;7(6):761-769.

111. Perez-Iglesias R, Crespo-Facorro B, Martinez-Garcia O, et al. Weight gain induced by haloperidol, risperidone and olanzapine after 1 year: findings of a randomized clinical trial in a drug-naive population. Schizophr Res. 2008;99(1-3):13-22.

112. Lipkovich I, Citrome L, Perlis R, et al. Early predictors of substantial weight gain in bipolar patients treated with olanzapine. J Clin Psychopharmacol. 2006;26(3):316-320.

113. Citrome L, Holt RI, Walker DJ, Hoffmann VP. Weight gain and changes in metabolic variables following olanzapine treatment in schizophrenia and bipolar disorder. Clin Drug Investig. 2011;31(7): 455-482.

114. CONSORT. The CONSORT statement. Available from: http://www. consort-statement.org/consort-statement/. Accessed August 20, 2013.

115. Xu L, Li J, Zhang M, Ai C, Wang L. Chinese authors do need CONSORT: reporting quality assessment for five leading Chinese medical journals. Contemp Clin Trials. 2008;29(5):727-731.

116. Treuer T, Liu CY, Salazar G, et al. Use of antidepressants in the treatment of depression in Asia: guidelines, clinical evidence, and experience revisited. Asia Pac Psychiatry. 2013;5(4):219-230.

117. Wang CH, Feng YG, Wang DH. [A double-blind randomized controlled study of olanzapine and clozapine on treatment of schizophrenia]. Shanghai Archives of Psychiatry. 2002;14(3):143-145. Chinese.

118. Wang YC, Yang CC, Bai YM, Kuo TB. Heart rate variability in schizophrenic patients switched from typical antipsychotic agents to amisulpride and olanzapine. 3-month follow-up. Neuropsychobiology. 2008;57(4):200-205.

119. Chiu CC, Chen CH, Chen BY, Yu SH, Lu ML. The time-dependent change of insulin secretion in schizophrenic patients treated with olanzapine. Prog Neuropsychopharmacol Biol Psychiatry. 2010;34(6): $866-870$.

120. Huang $\mathrm{HH}$, Wang YC, Wu CL, et al. TNF-alpha $-308 \mathrm{G}>\mathrm{A}$ polymorphism and weight gain in patients with schizophrenia under longterm clozapine, risperidone or olanzapine treatment. Neurosci Lett. 2011;504(3):277-280.

121. Yang XH, Huang JZ, Yan HS. [Open-label trial of olanzapine in the treatment of 70 patients with schizophrenia]. Shanghai Archives of Psychiatry. 2002;14(2):94-96. Chinese.
Neuropsychiatric Disease and Treatment

\section{Publish your work in this journal}

Neuropsychiatric Disease and Treatment is an international, peerreviewed journal of clinical therapeutics and pharmacology focusing on concise rapid reporting of clinical or pre-clinical studies on a range of neuropsychiatric and neurological disorders. This journal is indexed on PubMed Central, the 'PsycINFO' database and CAS.

\section{Dovepress}

The manuscript management system is completely online and includes a very quick and fair peer-review system, which is all easy to use. Visit $\mathrm{http}: / / \mathrm{www}$.dovepress.com/testimonials.php to read real quotes from published authors. 